\title{
3D Seismic Imaging of a Near-Surface Heterogeneous Aquifer: A Case Study
}

\author{
J.-L. Mari ${ }^{1}$ and G. Porel ${ }^{2}$ \\ 1 Institut français du pétrole, IFP school, 1-4 avenue de Bois-Préau, 92852 Rueil-Malmaison - France \\ 2 Université de Poitiers, UMR 6532 HydrASA, 40 avenue du recteur Pineau, 86022 Poitiers - France \\ e-mail: j-luc.mari@iff.fr - gilles.porel@hydrasa.univ-poitiers.fr
}

\begin{abstract}
Résumé - Imagerie sismique 3D d'un aquifère hétérogène proche de la surface - Différentes acquisitions sismiques ont été réalisées sur le site hydrologique expérimental de Poitiers (France). Ce papier montre comment la sismique 3D peut être mise en oeuvre et traitée pour décrire un aquifère hétérogène proche de la surface. Le dispositif d'acquisition a été choisi pour obtenir à la fois une imagerie par réfraction et par réflexion. La sismique réfraction a permis d'obtenir une image en profondeur du toit de l'aquifère carbonaté. Une analyse géostatistique et un filtrage par krigeage factoriel ont permis d'améliorer l'image sismique et de rechercher des structures à grande échelle. Deux directions de structure ont ainsi pu être mises en évidence. La direction principale est orientée N90 et la direction secondaire N50. Ces deux directions ont été retenues pour implanter les puits déviés $\mathrm{C} 3$ et $\mathrm{C} 4$. La sismique réflexion a permis d'obtenir un bloc de vitesse $3 \mathrm{D}$ en profondeur. $\mathrm{La}$ résolution verticale a pu être améliorée par déconvolution après conversion profondeur. Un filtre de Wiener, défini au puit de référence $\mathrm{C} 1$ a permis de convertir les traces sismiques en vitesses d'intervalle. Les résultats obtenus ont été validés sur quatre puits (MP6, MP5, M8, M9) où des diagraphies acoustiques avaient été au préalable enregistrées. Le bloc de vitesse sismique montre la forte hétérogénéité du réservoir aquifère et confirme les orientations principales des structures mises en évidence par réfraction. À une profondeur donnée, la distribution des vitesses sismiques met en évidence des chemins préférentiels de connexion entre puits. À titre d'exemple des tests d'interférence et des pompages confirment la connexion hydraulique entre les puits M13 et M21, situés dans une zone à vitesse sismique lente à la profondeur de $88 \mathrm{~m}$.
\end{abstract}

Abstract - 3D Seismic Imaging of a Near-Surface Heterogeneous Aquifer: A Case Study Different surface seismic surveys have been recorded on an experimental hydrogeological site that has been developed for several years near Poitiers (France). The paper shows how 3D seismic imaging can be used to describe the near-surface heterogeneous aquifer. The acquisition spread is designed to perform both $3 D$ refraction and reflection seismic surveying. Refraction survey enables us to obtain a $3 D$ image in depth of a low velocity superficial zone contrasting with the underlying water - bearing carbonates. Variogram analysis and geostatistical filtering allow to filter random and structured acquisition noise. Factorial kriging is used to filter the small scale structures (cubic structure with a range of $55 \mathrm{~m}$ and nugget) in order to make the large scale structures appear and to determine their orientation: a main orientation N90 and a secondary orientation N50. These two directions have been selected to implement two deviated wells $C 3$ and C4. Reflection survey enables us to get a 3D seismic pseudo velocity block in depth. The vertical resolution is enhanced thanks to deconvolution after depth conversion. A Wiener filter, defined at a reference well Cl has been applied to the seismic traces to convert into velocity the amplitude sections. The results obtained are 
validated at four wells (MP6, MP5, M8, M9) in which acoustic data have been recorded. The 3D seismic pseudo velocity block shows the large heterogeneity of the aquifer reservoir in the horizontal and vertical planes, confirms the main structural orientations (N90 and N50) pointed out by refraction survey. At a given depth, the velocity distribution shows preferential connections between wells. As an example, well pumping tests and pressure interference confirm the hydrodynamic connection between wells M13 and M21 defined by a low velocity zone at $88 \mathrm{~m}$ depth.

\section{INTRODUCTION}

Many underground aquifers were developed as experimental sites during the past decade. These sites are designed for insitu measurements and calibration of flow, transport and/or reactions in underground reservoirs that are heterogeneous by nature.

The University of Poitiers (France) had a Hydrogeological Experimental Site (HES) built nearby the Campus for the sole purpose of providing facilities to develop long-term monitoring and experiments for a better understanding of flow and transfers in fractured rocks (Bourbiaux et al., 2007). The site is set up over a confined Jurassic fractured limestone of about $100 \mathrm{~m}$ in thickness beneath $20 \mathrm{~m}$ of Tertiary clays. The building phase started in 2002 and up to now, 35 wells have been bored over the whole thickness of the reservoir. Most wells dispose of documented drilling records and logs of various nature, among which are gamma-ray, temperature, and acoustic. In addition, two wells were entirely cored. Among the teaching, research and engineering activities (sub-surface geophysics, geochemistry monitoring, in-situ decontamination, vadose-zone hydrology, groundwater) carried out on the site and shared between several teams from France and Europe, a small group in Poitiers has been interested in addressing the hydraulic properties of the fractured reservoir by means of hydraulic tests (Bernard et al., 2006; Kaczmaryk and Delay, 2007). To sum up, the aquifer answers almost evenly to the hydraulic stress of a pumped well, with pressure depletion curves merged together in time and amplitude whatever the distance from the pumped well. This merging is assumed to be the consequence of a local karstic flow in open conduits that have been unclogged by the drilling and pumping works. The presence of pervasive karstic drains is supported by recent logs in the wells using optic imaging. Almost all the wells have shown caves and conduits cut by the walls of the boreholes with sometimes mean apertures of $0.2-0.5 \mathrm{~m}$. These conduits are mostly enclosed in three thin (1 m thickness) horizontal layers at 50, 88 and $110 \mathrm{~m}$ depth. Of course, these layers are intercepted by vertical wells and this potentially results in a good connection between wells and karstic drains. This connection is mainly controlled by the degree to which drains are re-opened in the vicinity of the well. In the end, it appears crucial to better image the geometry of the reservoir with a resolution compatible with on the one hand the scale of a well and, on the other hand the scale of the entire experimental disposal. High resolution geophysical tools seem well designed to undertake that kind of investigation.

The present publication shows the benefit of using 3D seismic surveys to describe the near surface aquifer. The acquisition of usable seismic data is particularly difficult for low-depth reservoirs underlying a thick weathered zone, such as the aquifer studied here. In the paper, we propose to show the benefit of combining both 3D refraction and reflection seismic surveying in order to extract structural information from data recorded in near surface acquisitions.

\section{PRELIMINARY STUDIES AND SPREAD DESIGNS}

Different surface seismic surveys were attempted with different acquisition schemes. The selected recording spread is composed of 48 single geophones. The sources used were either a detonating impulse source or a mini vibrator system. The distance between 2 adjacent geophones is $5 \mathrm{~m}$. The time sampling interval is $0.25 \mathrm{~ms}$ and the recording length is $0.5 \mathrm{~s}$. For a given recording spread several shot points were fired. A direct shot and a reverse shot were fired in line to obtain 2D seismic images. Several shots were fired cross line to obtain 3D seismic images.

Figure 1a shows an example of an in-line shot point obtained with the impulse source. The data are presented both in the time distance domain and in the F-K domain. The main energetic wave fields are the low and high apparent velocity pseudo-Rayleigh waves and the direct and refracted body waves.

The shape of the refracted wave shows that the refractor is strongly disturbed. This is confirmed by the analysis of the picked times of the refracted arrivals. Refraction signals enable us to obtain images of the top surface of the aquifer. This is useful in the present case as the aquifer top surface is strongly disturbed as a result of the presence of caves of karstic origin filled in by clayey surface erosion material. The results obtained in refraction surveying will be presented in the next part of the paper.

For seismic imaging based on reflected waves, it is necessary to be able to separate weak reflected events from high 

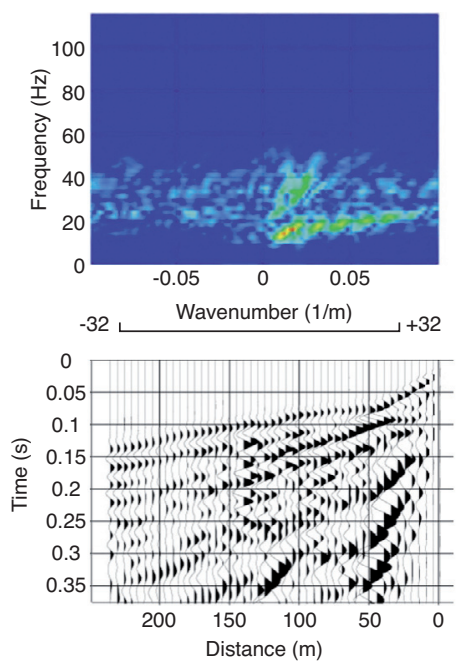

a
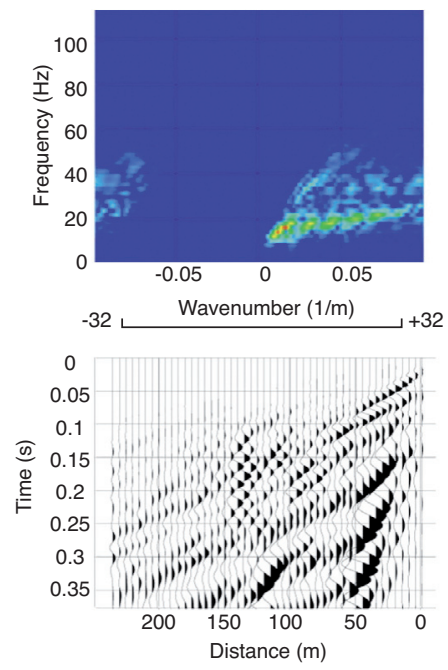

b

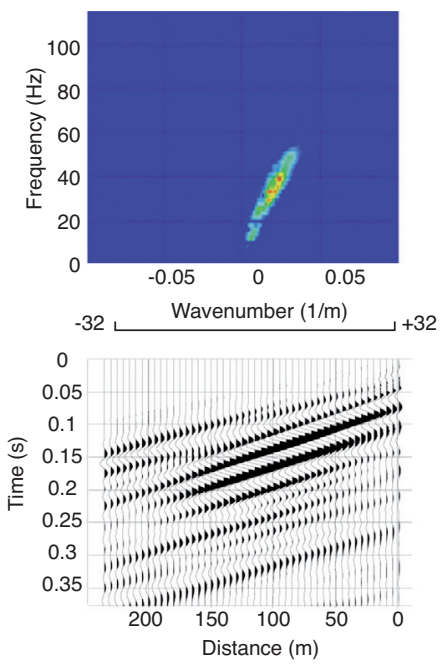

C

Figure 1

In line shot point and surface waves. a: Raw data. b: Direct wave and slow Rayleigh wave. c: Fast Rayleigh wave Normalised displays.

energy surface waves such as pseudo-Rayleigh waves. Wave separation is a crucial step in the processing sequence. Its procedure is illustrated in Figures 1 and 2. In the specific field case, Mari (2006) has shown the benefit of combining two different wave-separation methods in order to remove all the energetic wave-field. The conventional F-K method is used to filter surface waves and converted refracted waves. The SVD method (Singular Value Decomposition) is then used to extract refracted waves. Hence, in practice, before performing the SVD filtering, a flattening operation on the initial data is applied to obtain an infinite apparent velocity for the selected wave (Mari et al., 1999). After SVD filtering, an inverse flattening operation is performed to put the data in their initial position. For refracted waves, the flattening preprocessing is obtained by time shifting the data; the time shifts are derived from the picking of the first arrival times.

The wave separation procedure has been done in several different steps. Each step includes:

- the extraction of a given wavefield by a specific filter (FK or SVD),

- the subtraction of the estimated wavefield from the input section to obtain a residual section,

- the residual section becomes the input section for the following step.

In the first step, the wave separation procedure has been used to extract, by F-K filter, the direct wave and the slow (low apparent velocity) Rayleigh wave (Fig. $1 \mathrm{~b}$ ). In the second step, the procedure has been applied to extract the fast (high apparent velocity) Rayleigh wave (Fig. 1c). The residual section exhibits negative apparent velocity events which are converted refracted waves that have been extracted in the third step (Fig. 2a). The separation procedure has then been applied to extract the refracted wave (SVD filtering, Fig. 2b). The residual seismic section thus obtained is shown in Figure $2 c$. It clearly shows infinite apparent velocity events which are associated with reflected waves. The reflected wave which appears at $0.75 \mathrm{~ms}$ is associated with a reflector situated inside the reservoir at a depth of $100 \mathrm{~m}$. One can also notice that the strongest surface waves are mainly located in the near offsets, up to $50 \mathrm{~m}$ (Fig. 1 b).

Seismic tests with the mini vibrator system have shown that the data are highly corrupted both by surface waves and a strong energetic aliased air wave, leading to an additional difficulty in wave separation. Moreover spread tests have shown that cross spread designs are well adapted to record data for 3D reflection seismic imaging.

These preliminary studies lead us to select the following spreads for 3D imaging. The detonating impulse source has been selected to record high frequency data and to reduce the air wave effect. To reduce the duration of acquisition, it has been decided to use the same receiver spread for refraction and reflection seismic surveying. To preserve the high frequency content of the data and to have an accurate picking of the refracted wave, a single geophone per trace has been used. To avoid any spatial aliasing, a $5 \mathrm{~m}$ distance 


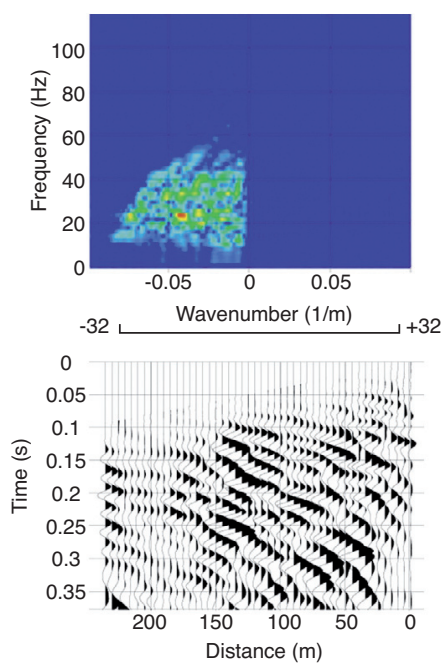

a
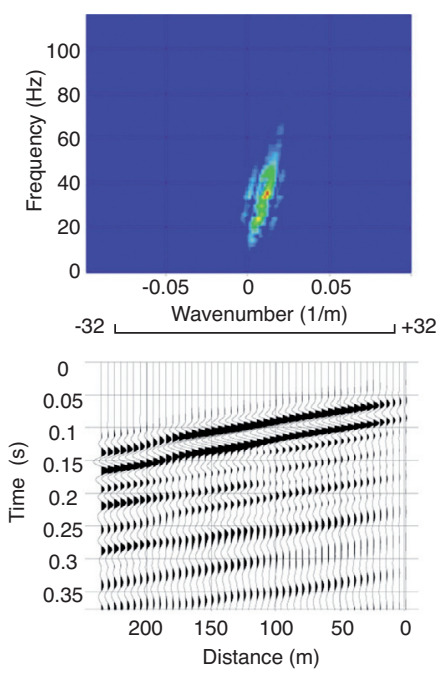

b
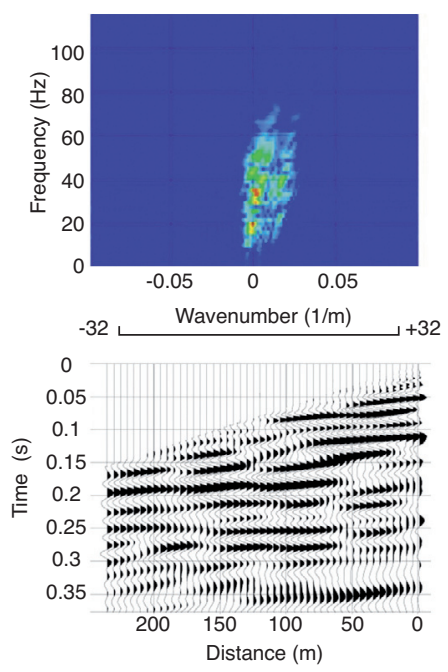

C

\section{Figure 2}

Refracted waves and reflected waves. a: Converted refracted waves. b: Refracted waves. c: Reflected waves.

Normalised displays.

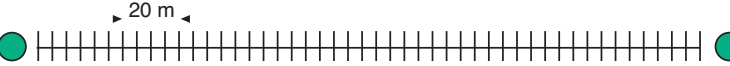

\section{○}

O

○

in line shot point for 2D

Cross line shot point for 3D

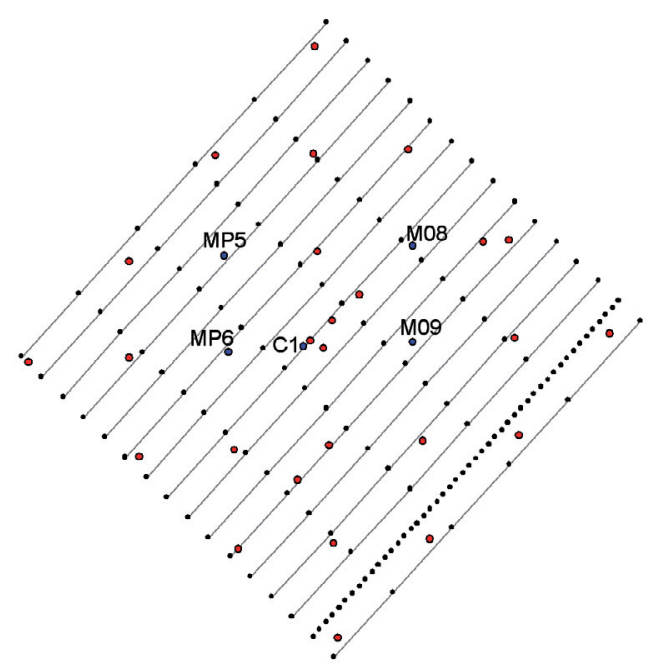

b

Figure 3

a

Seismic spreads and field implementation of seismic lines.

a: Seismic spreads: a direct shot and a reverse shot are fired in line to obtain 2D seismic images. Several shots are fired cross line to obtain 3D seismic images.

b: Seismic line implementation: the distance between 2 adjacent lines is $15 \mathrm{~m}$. Red points indicate well locations.

between two adjacent geophones has been selected. Due to the extension of the area, the length of the seismic line cannot exceed $250 \mathrm{~m}$, in the in line direction. Consequently, a 48-channel recorder has been used. In the cross line direction, the extension of the area does not exceed $300 \mathrm{~m}$. As a result, 21 receiver lines have been implemented, with a 15 $\mathrm{m}$ distance between adjacent lines. For the refraction survey, a direct shot and a reverse shot have been recorded per receiver line. For the reflection survey, 3 shot points in the cross line direction have been fired per receiver line. The 

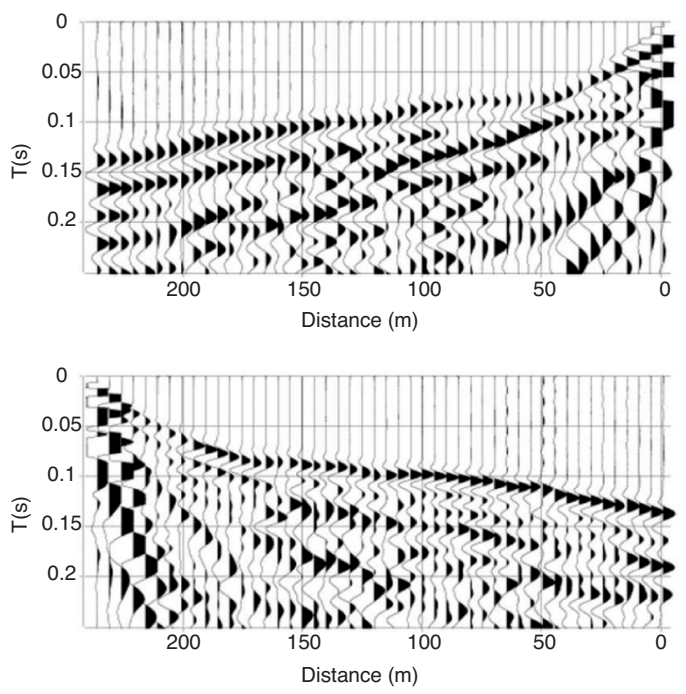

a

Figure 4

Example of an in line profile for refraction seismic surveying.

a: Direct and reverse in line shot points. b: $\mathrm{T}$ minus and delay curves.
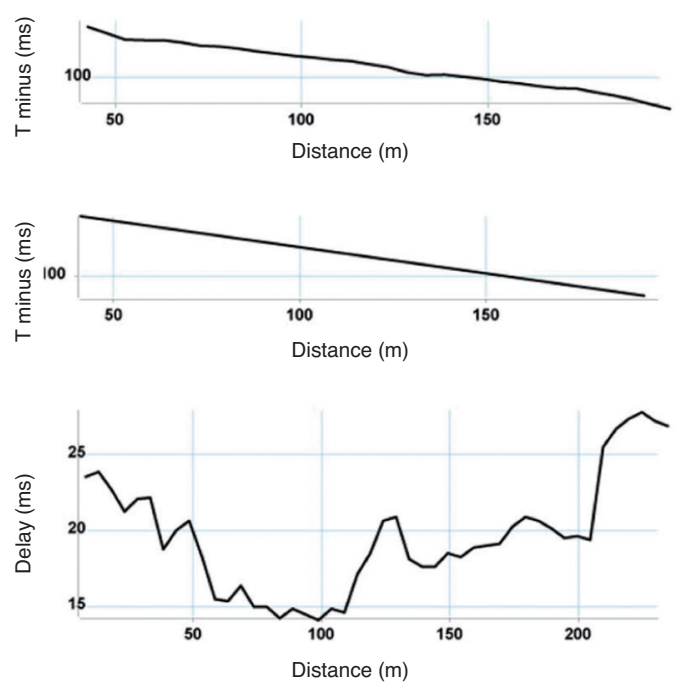

b range of offsets has been selected to optimise the quality of the seismic image in the reservoir zone, between 40 and $130 \mathrm{~m}$. The minimum offset distance has been chosen equal to $40 \mathrm{~m}$ to reduce the influence of the surface waves (Figs. $1 b, c)$. The distance between 2 adjacent shot points in the cross line direction has been chosen equal to $10 \mathrm{~m}$. Figure 3 shows the selected seismic spreads and the map locating the seismic lines. The red points indicate the location of the wells. Refraction seismic uses in line shots for 2D profiles along geophone lines. 3D is for reflection seismic with cross line shots.

\section{REFRACTION SEISMIC SURVEYING}

Refraction imaging of the subsurface is based on the analysis of refraction time-distance curves; this requires recordings where geophones are aligned with shot points. To obtain the true velocity of each marker, its dip and thickness, we need to have time distance curves in both directions, i.e. updip shooting and downdip shooting. The best-known methods are Hagedoorn's Plus-Minus method (1959) and the generalised reciprocal method (GRM) proposed by Palmer (1986). The GRM method is actually a generalisation of the Plus-Minus method. Both methods use the notion of delay time. The Plus-Minus method is widely used in refraction prospecting. Picked times give access to the $\mathrm{t}+$ and $\mathrm{t}$ - curves. The $\mathrm{t}$ - curve provides the velocity of the refractor. If the velocity of the refractor is constant along the seismic line, the t- curve can be approximated by a straight curve, the slope of which allows us to determine the velocity of the refractor. The $t+$ curve gives a time image of the refractor depth (delay times). The delay curve can be converted into depth, if the velocity of the medium situated above the refractor is known. Here, it is given by the slope of the direct wave. The medium situated above the refractor is defined as the weathering zone (WZ). Figure 4 shows the results obtained on line 9. It shows the direct and reverse shot points, the raw t- curve and its associated straight curve, and the delay curve (ms). The velocity of the refractor has been evaluated at $3350 \mathrm{~m} / \mathrm{s}$, the velocity of the $\mathrm{WZ}$ at $850 \mathrm{~m} / \mathrm{s}$.

The refraction study has been done line after line in order to obtain both a delay time map and a depth map of the weathering zone (WZ). The results obtained are shown in Figure 5. The sampling interval in the cross line direction equals the distance between two adjacent lines, i.e. $15 \mathrm{~m}$. In order to obtain maps with a homogeneous sampling interval both in cross line and in line directions, the maps (Figs. $5 a, c$ ) have been linearly interpolated in the cross line direction. After interpolation, the maps (Figs. 5 b, d) show the structural features at the top of the reservoir. The thickness of the weathering zone varies between 10 and $30 \mathrm{~m}$.

Geostatistical methods have been used to study the spatial variability of the seismic maps and to detect some footprints due to the acquisition procedure. Variograms are used to 

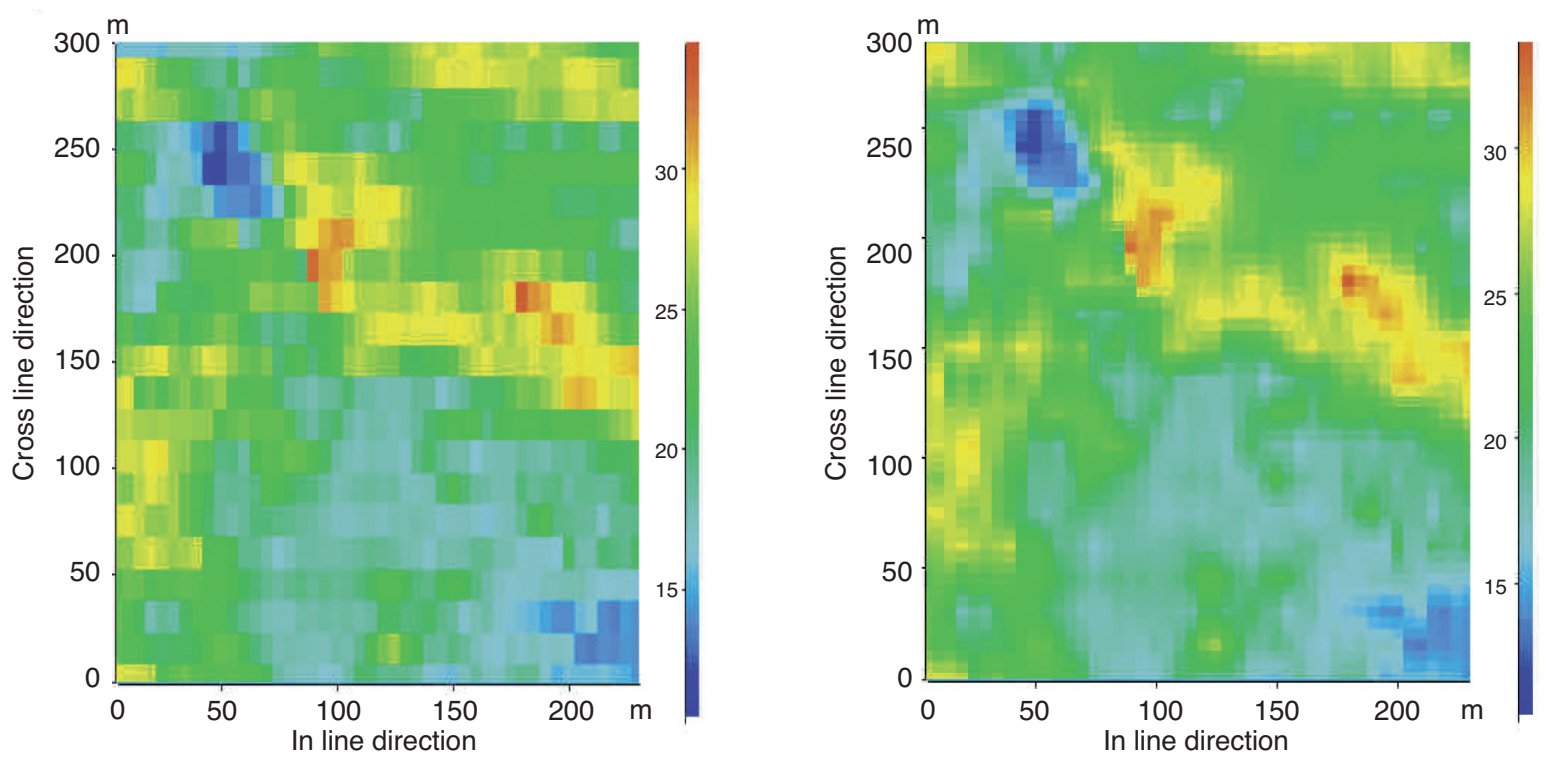

a
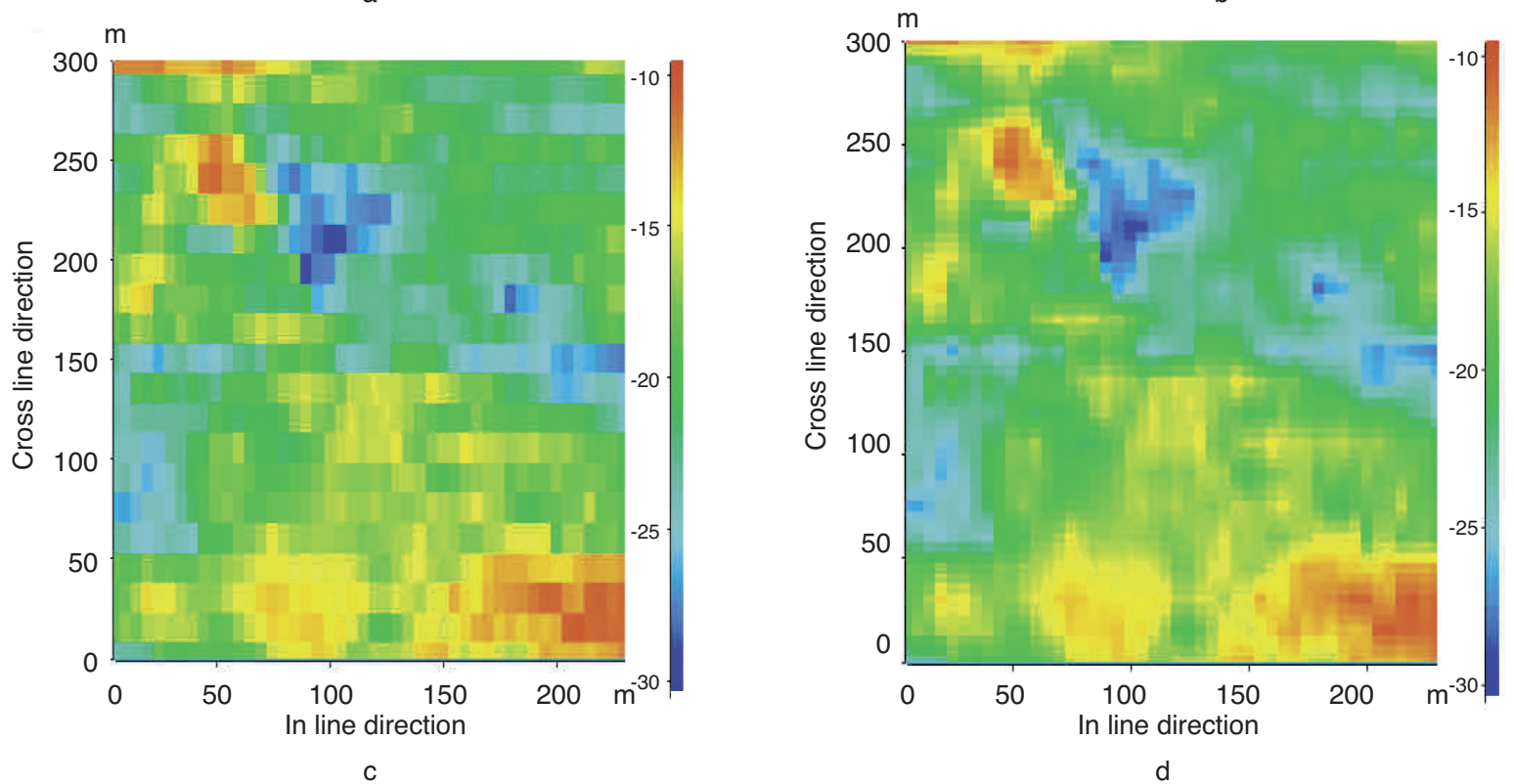

Figure 5

Delay time map and a depth map of the weathering zone (WZ).

a: Raw delay time map $(5 \mathrm{~m} \times 15 \mathrm{~m})$.

b: Delay time map after linear interpolation in the cross line direction $(5 \mathrm{~m} \times 5 \mathrm{~m})$.

c: Raw depth map $(5 \mathrm{~m} \times 15 \mathrm{~m})$.

$\mathrm{d}$ : Depth map after linear interpolation in the cross line direction $(5 \mathrm{~m} \times 5 \mathrm{~m})$.

describe the geological continuity of "homogeneously heterogeneous" properties (Caers, 2005). This means that variograms are best suited for describing the continuity of geological structures. In 2D space, a variogram map (variograms calculated for several directions or azimuths) can be used to identify the direction of better continuity.
The cross line direction of the variogram map is arbitrarily defined as the north direction (NO), consequently the in line direction is defined as N90. The results of the geostatistical analysis are shown in Figure 6 for the delay map. The variogram map clearly shows that, at small scale, there is an apparent better continuity in the in line direction (N90) than in the cross line direction 
(N0). Figure 6a shows the experimental variograms in both directions (N0 and N90). Filtering of the map requires the variogram to be known for all distances, not only those experimental distances between sample data locations. To do so, the experimental variograms are to be modeled (Fig. 6b). Variogram modeling consists in fitting analytical models defined by a few parameters (range, sill, nugget effect) to the experimental variograms.

Firstly, focusing on the direction of better continuity

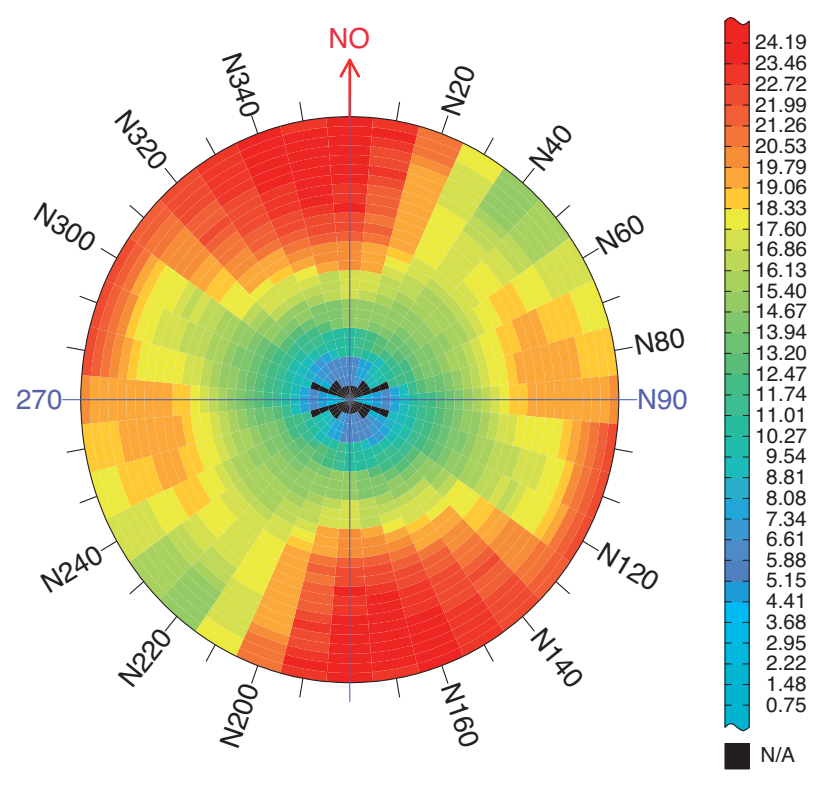

a

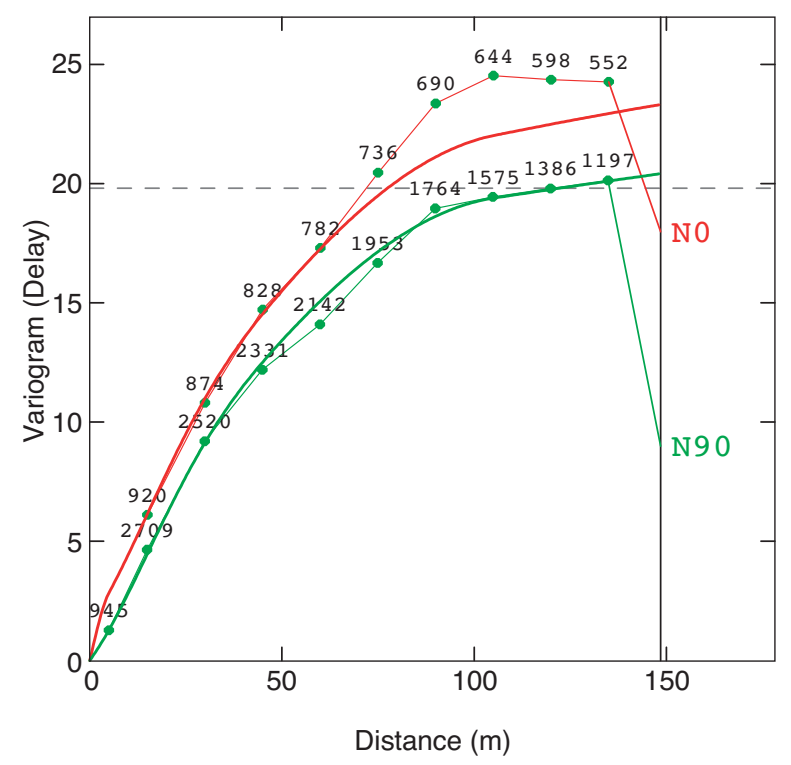

b
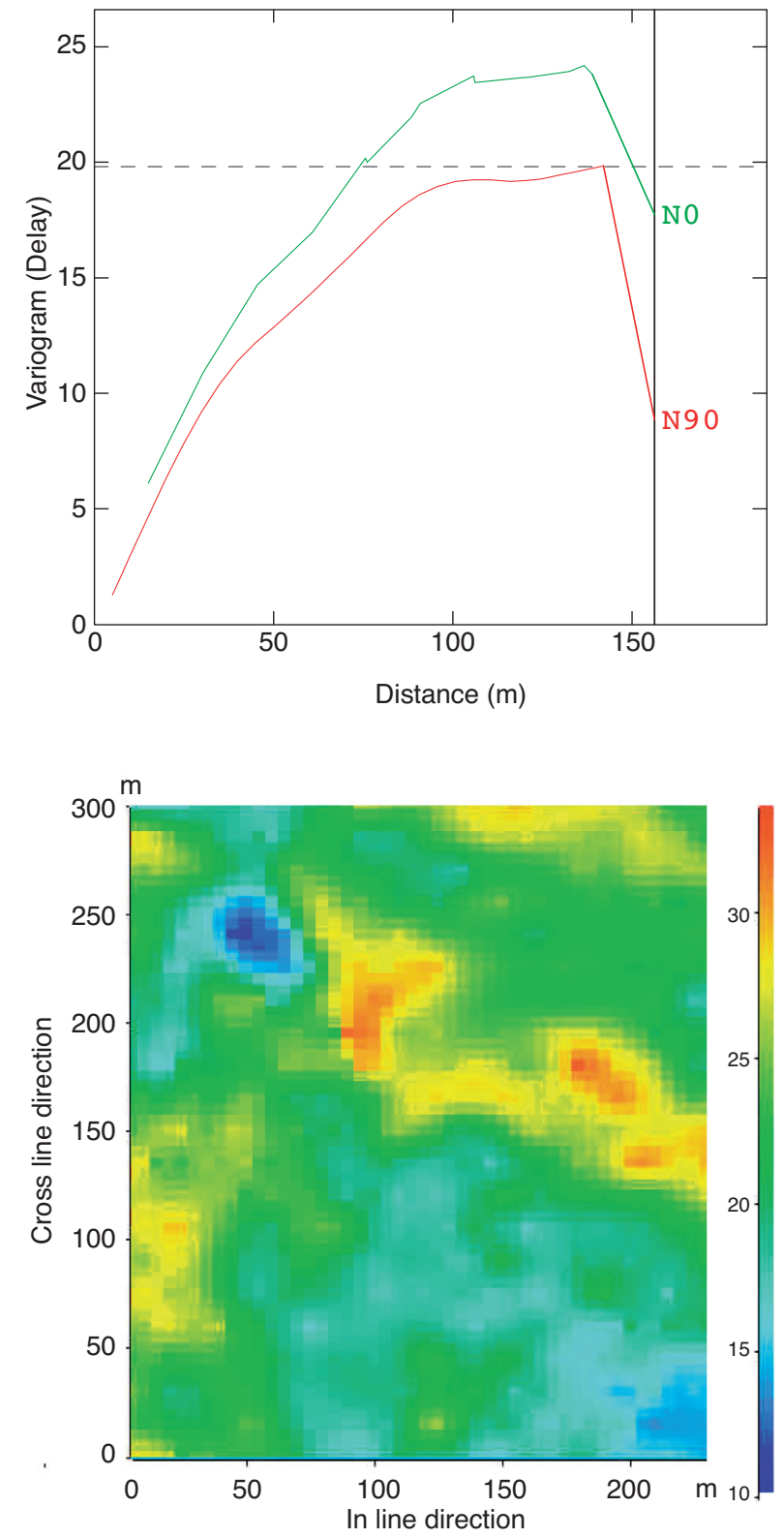

c

Figure 6

Geostatistical analysis of the delay map.

a: Variogram map and experimental variograms in the in line direction (N90) and in the cross line direction (N0), b: variogram modeling, c: delay map after filtering by factorial kriging. 
(N90), the experimental variogram can be modeled by the combination of various basic structures:

- A small nugget effect that could be interpreted as random noise (even in this inline direction);

- A cubic structure with a range equal to $50 \mathrm{~m}$, consistent with the size of the geological heterogeneities (50 m width);
- Two long range structures (both spherical with ranges equal to $100 \mathrm{~m}$ and $400 \mathrm{~m}$ ).

The spatial structure presents an additional variability source in the cross line direction, attributable to acquisition artifacts. This component is modeled by a spherical basic structure with a range equal to $5 \mathrm{~m}$ in the cross line direction
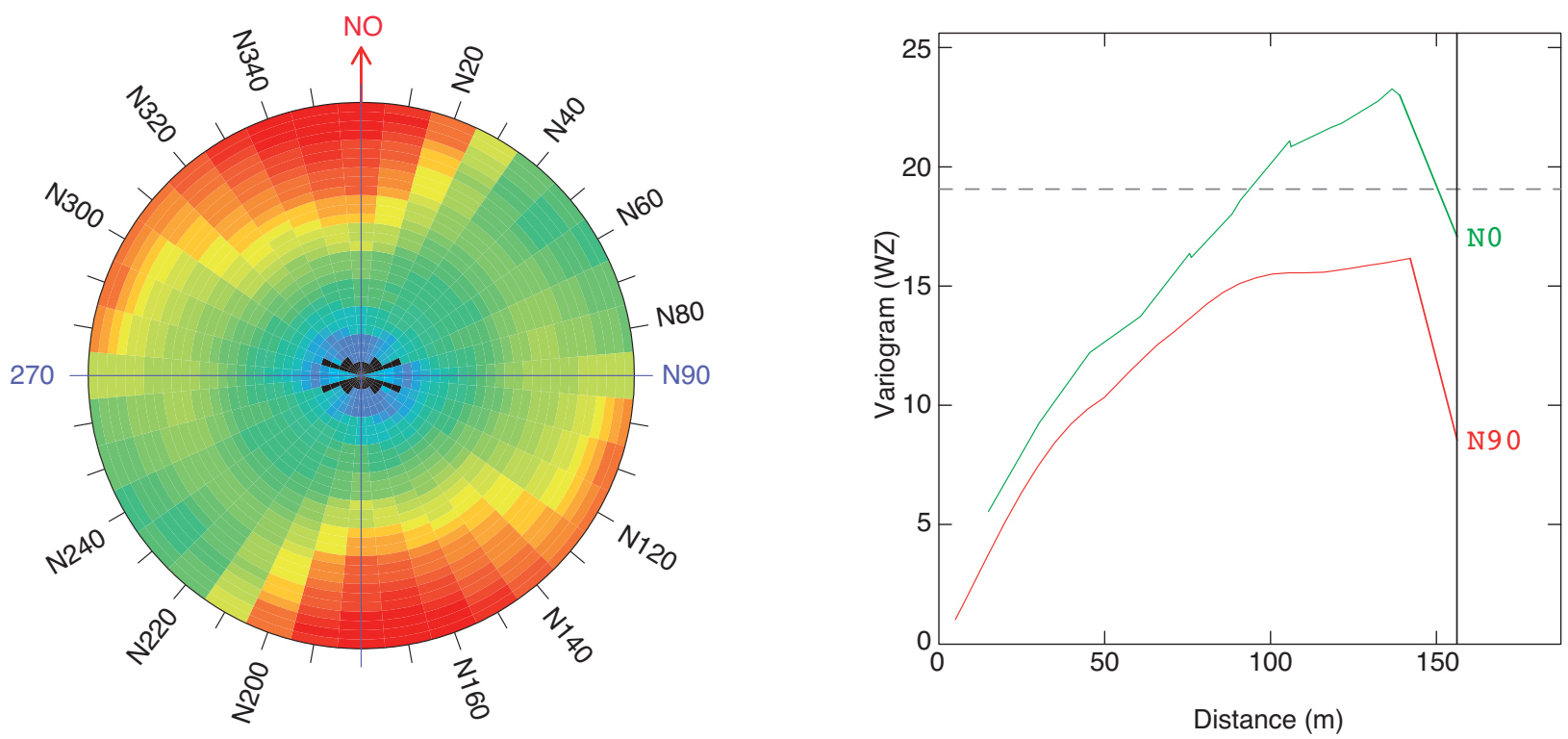

a

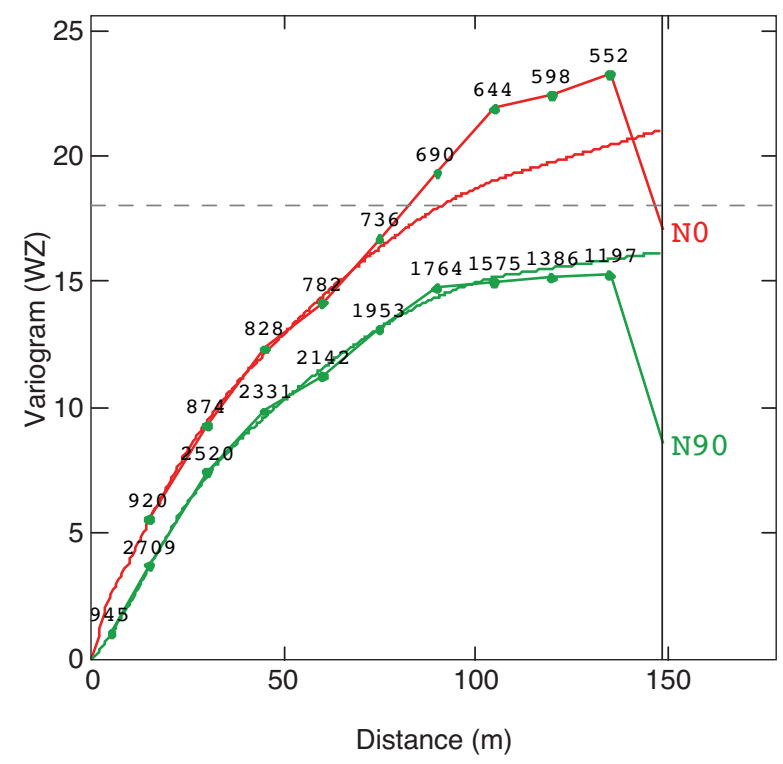

b

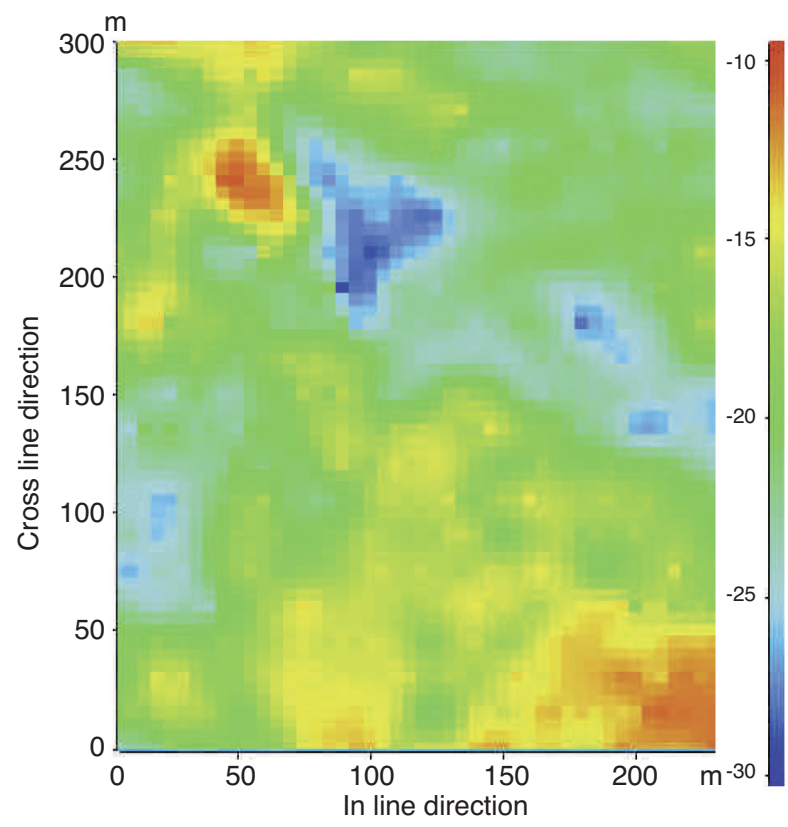

Figure 7

Geostatistical analysis of the WZ depth map.

a: Variogram map and experimental variograms in the in line direction (N90) and in the cross line direction (N0), b: variogram modeling, c: WZ depth map after filtering by factorial kriging. 
only (zonal anisotropy). This range is chosen in consistence with the expected mapping resolution $(5 \mathrm{~m} \times 5 \mathrm{~m})$. Also, the large scale spherical model has a smaller range $(275 \mathrm{~m}$, compared to $400 \mathrm{~m}$ ) in the cross line direction. However, the large scale spatial structure will not influence the filtering of the acquisition artifacts. The nugget effect and the small scale spherical model (5 $\mathrm{m}$ in the cross line direction), which have no physical meaning and are due to acquisition artefacts, have to be filtered during the estimation process. This filtering is achieved using factorial kriging (Matheron, 1982; Chilès and Delfiner, 1999) and the filtered map is shown in Figure $6 \mathrm{c}$. Basically, factorial kriging assumes that the variogram of raw data is made of several nested structures (embedded variograms) with increasing correlation lengths. It is then stated that each embedded variogram can be associated with a "factor" in the data. Filtering a given factor is just performing in kriging raw data with a variogram truncated from the embedded factor one want to hidden. Factorial kriging relies on this association between each basic variogram structure and a physical interpretation. This association is meaningfull in our case, as the variogram fitting itself is driven from the physical interpretation: random noise, then structured noise due to acquisition artefacts in the cross line direction, etc. Slightly different basic structures could have been chosen for the variogram fitting; however, it is important to keep in mind that as long as the overall variogram fits the experimental variograms then kriging will give similar and consistent results.

The same procedure has been used for the WZ depth map. The results are consistent with those obtained with the delay map. The variogram map and the experimental variograms in the cross line (N0) and in line (N90) directions are shown in Figure 7a. The experimental variograms, associated with the directions N90 (better continuity) and N0, have been modeled by the same combination of the basic structures used for Delay variograms. The results of variogram modeling and filtering by factorial kriging are shown in Figures $7 \mathrm{~b}$ and $\mathrm{c}$ respectively.

Substracting the filtered map from the raw one allows us to detect an anomalous line around $Y=150 \mathrm{~m}$ (Fig. 8a). The WZ depth map is derived from the 21 delay lines, which are depth converted line after line. The residual map (the difference between the raw map and the filtered map) shows that the depth of the weathering zone at the location of the anomalous line is underestimated. This is due to a local under estimation of the velocity in the weathering zone. The process is then re-applied after the suppression of this line. It is interesting to note that the cross line variability attributed to footprints is actually due to the anomalous line, as shown by the WZ raw variogram (Fig. $8 b$ ). This example shows that geostatistical tools can be used as quality control tools. Therefore, an omnidirectional variogram is computed, being mostly interested by the small scale variability, up to $50-75 \mathrm{~m}$. The variogram model is constituted by a nugget effect, a cubic structure with a range of $57 \mathrm{~m}$ and a long scale spherical structure with a range of $145 \mathrm{~m}$ (Fig. 8c). Finally, a kriging with the model so defined and a filtering of the nugget effect (random acquisition noise) are performed to obtain the filtered WZ depth map (Fig. 8d). Factorial kriging is used again to filter both the nugget effect and the small scale structures (cubic with a range of $55 \mathrm{~m}$ ) in order to obtain a map which makes the large scale structures appear. Figure 9a shows the resulting weathering depth map after filtering the small scale structures. The map enables us to identify the directions of the geological structure at the scale of the map. Figure $9 \mathrm{~b}$ shows that the azimuth of the main structure is N90, the reference being true North indicated by the arrow N0.

Refraction survey enables us to obtain a 3D image in depth of a low velocity surperficial zone contrasting with the underlying water - bearing carbonates. Variogram analysis and geostatistical filtering allow to detect an anomalous line and to filter random acquisition noise. Factorial kriging is used to filter the nugget effect and the small scale structures (cubic structure with a range of 55 $\mathrm{m})$ in order to make the large scale structures appear and to determine their orientation: a main orientation N90 is clearly visible and a secondary orientation N50 can be guessed. These two directions have been selected to implement two deviated wells: $\mathrm{C} 3$ and $\mathrm{C} 4$.

\section{REFLECTION SEISMIC SURVEYING}

For the last two decades 3-D seismic has progressed significantly. In many major oil companies 3D surveys increased exponentially from 1990 to 1996 to cover the majority of their offshore fields. Nowadays, acquisition of land 3-D seismic is also developing very quickly. 3-D seismic has reduced many uncertainties in oil and gas exploration and production (Chaouch and Mari, 2007). 3D data are now increasingly used for field development and production and not only as an exploration tool. In the oil industry, 3D seismic surveying requires important field equipment at the source (several vibrators), at the receivers (several tens of thousands of geophones, several hundred km of cable), and at the recorder (a central unit with at least 1500 active channels, several thousands of field digitiser units, power generators) leading geophysicists to obtain 3D seismic block with a fold reaching several hundreds (i.e. 960 in Middle East).

Pre-planning of the 3D surveys is then a fundamental step to ensure that the 3D data quality will meet requirements for geological studies (structural geology, stratigraphy and lithology). Pre-planning based on preliminary studies allows for an estimation of all characteristics of the future acquisition such as offset, fold and azimuth distributions, effects of surface obstacles, make up shots, etc. The pre-planning aims 

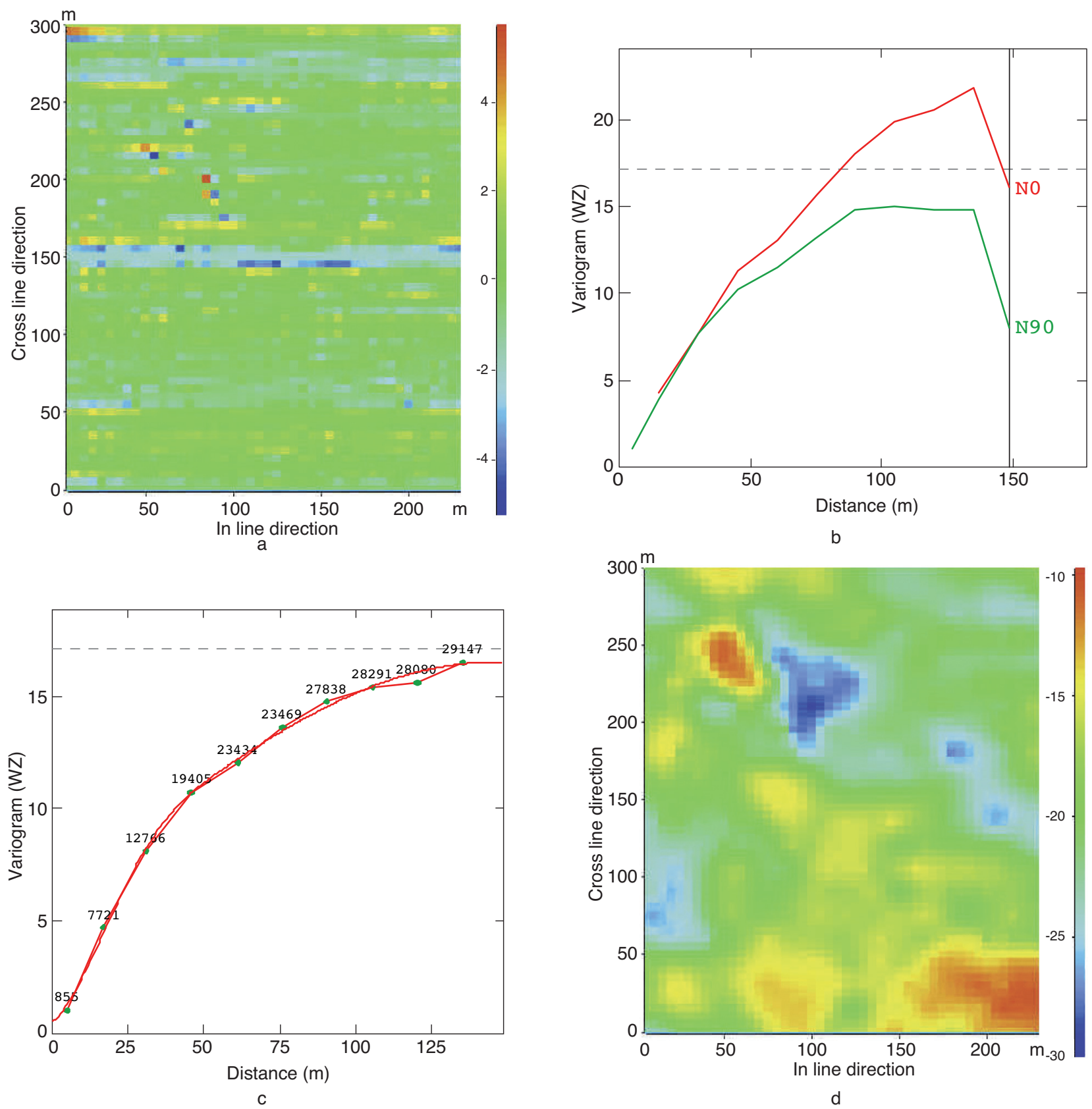

Figure 8

Geostatistical analysis of the WZ depth map after cancellation of an anomalous line.

a: Detection on the anomalous line.

b: Experimental variograms in the in line direction (N90) and in the cross line direction (N0).

c: Experimental omnidirectional variogram and modelling.

d: WZ depth map after filtering by factorial kriging based on omnidirectional variogram.

at defining the geological targets of the 3D, i.e. a near surface aquifer, with the associated geophysical parameters, design and costs. Our studied field case shows the possibility of recording very light $3 \mathrm{D}$ high resolution seismic data aiming to have an accurate description of the near surface heterogeneous aquifer.

The selected acquisition spread design and the associated pre-processing sequence (wave separation) have been 


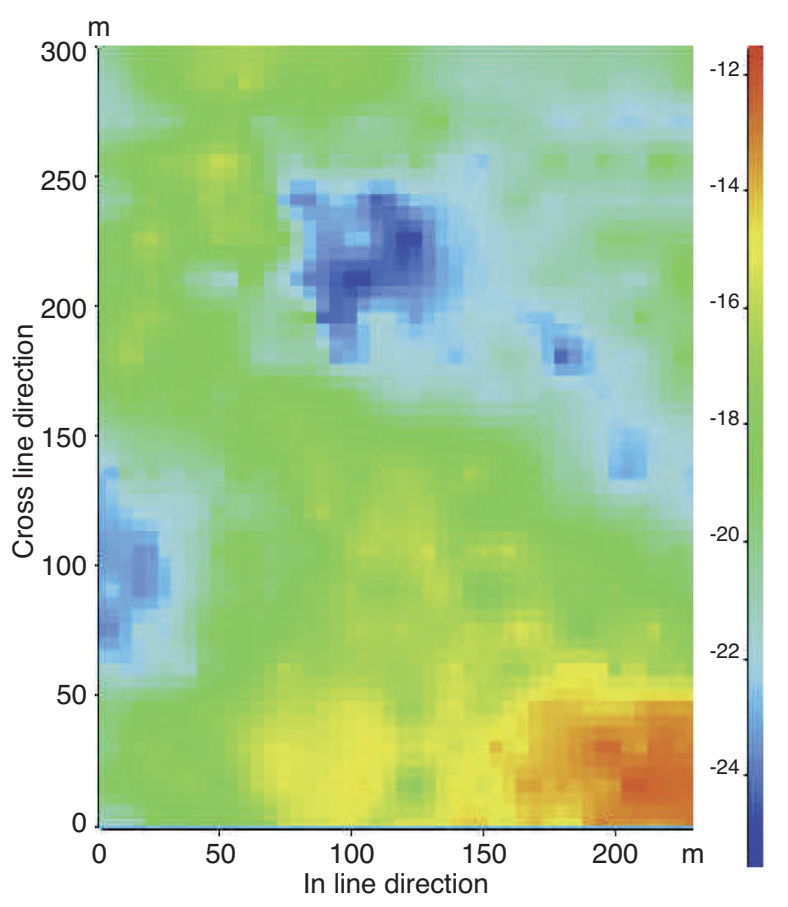

a

Figure 9

Orientation of the geological structures.

a: Weathering depth map after filtering of the small scale structures.

b: Orientation on the geological structures.

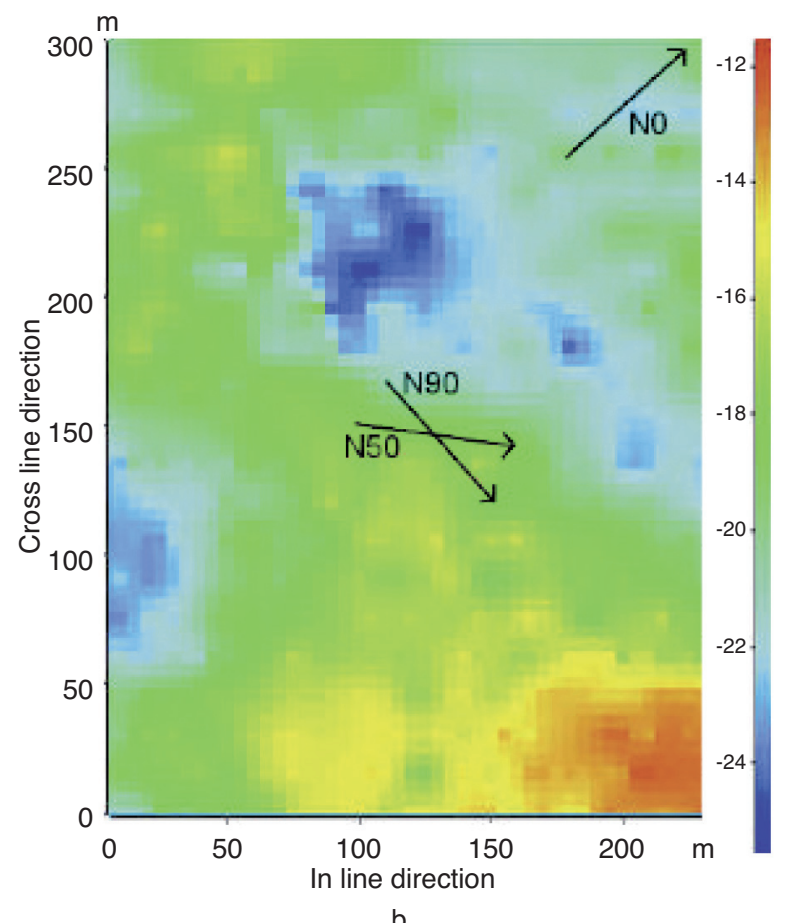

b described in the first part of the paper. The field equipment is reduced to a 48-active channels recorder, a template composed of 48 vertical geophones and small charges of dynamite ( $25 \mathrm{~g}$ per shot point) at each source point. 20 templates have been implemented. A template is a single receiver line composed of 48 geophones. The distance between 2 geophones is $5 \mathrm{~m}$. For each template location, 3 shot points (cross spread) are recorded with offsets ranging between $40 \mathrm{~m}$ to $60 \mathrm{~m}$. The cross line move up (distance between 2 adjacent templates in the cross line direction) is $15 \mathrm{~m}$. The geometry of acquisition leads us to obtain a single fold $3 \mathrm{D}$ block with a $2.5 \mathrm{~m} \times 5 \mathrm{~m}$ bin size. The 3D block is composed of 60 in line sections and 48 cross line sections. Figure 10 recaps the acquisition parameters and shows the shot point recorded on geophone line 11 with a $60 \mathrm{~m}$ source offset. Each shot point (cross spread) has been processed independently to obtain a single fold depth section with a sampling interval of $2.5 \mathrm{~m}$ (half the distance between 2 adjacent geophones) in the in line direction. The single fold depth sections are then merged to obtain the 3 D block.

Figures 11 and 12 show the first steps of the processing of the cross spread recorded on line 11 with a $60 \mathrm{~m}$ source offset.
After amplitude recovery (Fig. 11, top left) and deconvolution (Fig. 11, bottom left), the wave separation procedure is applied as follows:

- Extraction of the refracted wave by SVD filter (Fig. 11, top right).

- Subtraction of the refracted wave from the initial section to obtain the first residual section (Fig. 11, bottom right). The residual section shows mainly surface waves with low apparent velocities.

- Extraction of the low apparent velocity events by $F-K$ filter (Fig. 12, top left).

- Subtraction of the low apparent velocity events from the first residual section to obtain the second residual section (Fig. 12, bottom left).

The second residual section shows high apparent velocity seismic events with a poor lateral continuity which could be reflected or diffracted waves corrupted by some residual noise. In well $\mathrm{C} 1$ situated in the central part of the site, a Vertical Seismic Profile (VSP, Mari and Coppens, 2003) has been recorded. VSP data have been processed to obtain a time versus depth relationship and a velocity model (Mari, 2006). The velocity model has been used to apply the normal 
$3 \mathrm{D}$ reflection survey: cross spread

Template: single receiver line 3 shot points per template (Offsets: 40, 50, $60 \mathrm{~m}$ ) 48 receivers per line

Receivers spacing: $5 \mathrm{~m}$

Cross line move up: $15 \mathrm{~m}$ 60 in line sections 48 cross line sections

\section{Fold $=1$}

Bin size

in line: $2.5 \mathrm{~m}$

cross line: $5 \mathrm{~m}$

2880 bins

a

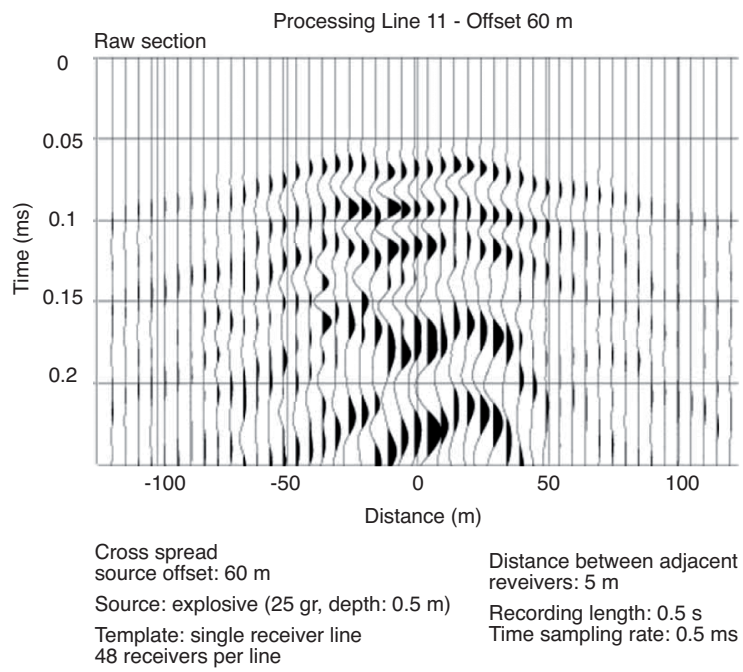

b

\section{Figure 10}

3D seismic surveying.

a: Acquisition parameters, b: example of raw shot point (cross spread).
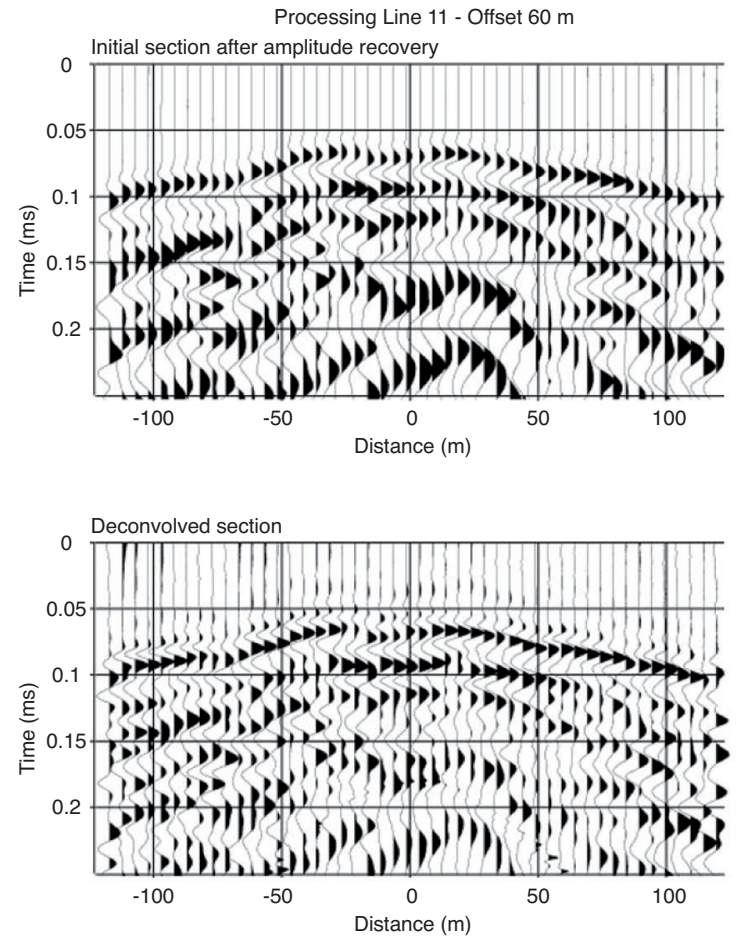
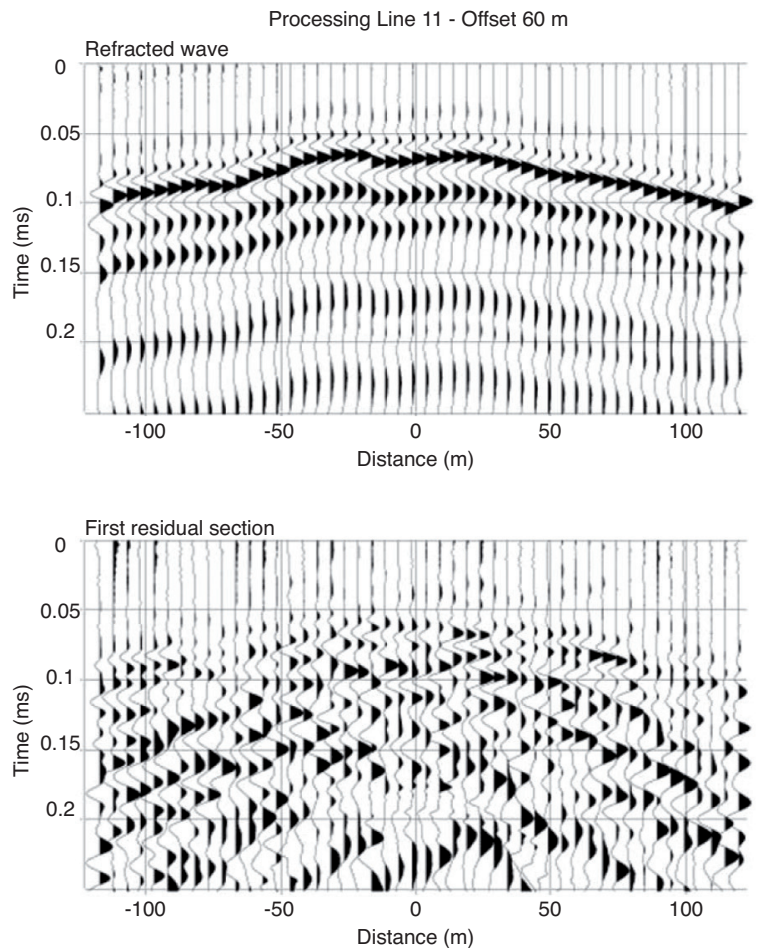

Figure 11

Processing of geophone line 11 with a $60 \mathrm{~m}$ source offset, top left: amplitude recovery, bottom left: deconvolution, top right: refracted wave, bottom right: first residual section. 

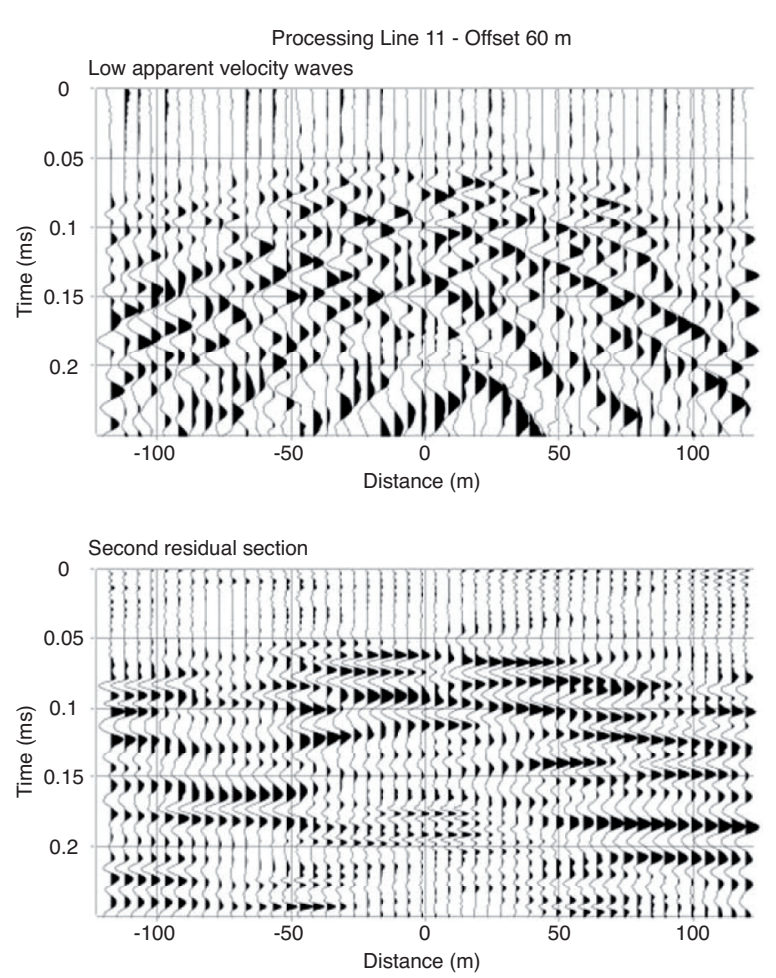

3D block: Seismic sections Line 11 offset $60 \mathrm{~m}$
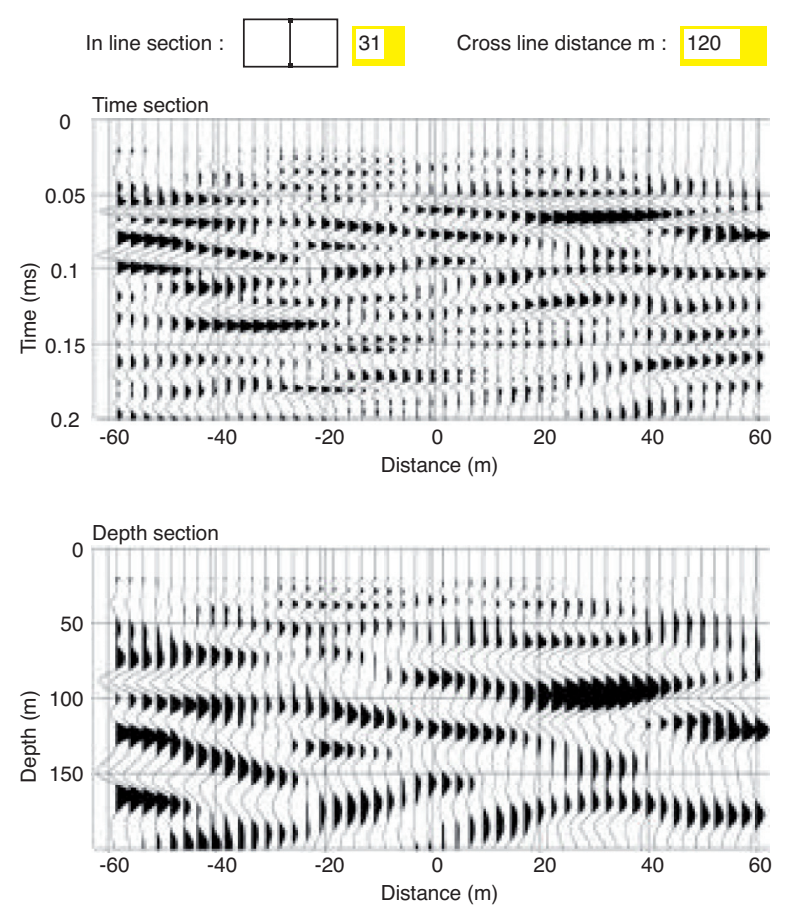

Figure 12

Time - depth conversion (geophone line 11 with a $60 \mathrm{~m}$ source offset), top left: low apparent velocity waves, bottom left: second residual section, top right: time section, bottom right: depth section.

move - out correction to the residual section in order to obtain a zero offset section at normal incidence. The same processing sequence has been applied to the 60 individual shot points to obtain 60 zero offset sections. The 60 sections have been merged to create the $3 \mathrm{D}$ block. The width of the block in the in line direction equals $120 \mathrm{~m}$. The abscissa zero indicates the location of the source line. The abscissa of the reflecting points varies between $-60 \mathrm{~m}$ and $+60 \mathrm{~m}$ in the in line direction, the distance between two reflecting points equals $2.5 \mathrm{~m}$. Due to the geometry of acquisition, the shot point recorded on geophone line 11 with a $60 \mathrm{~m}$ source offset becomes the in line section 31 (Fig. 12, top right). The VSP time versus depth law measured at well $\mathrm{C} 1$ has been used to convert the time sections into depth sections with a $0.5 \mathrm{~m}$ depth sampling interval. The depth conversion of time section 31 is presented in Figure 12 (bottom right). In the 30 to $120 \mathrm{~m}$ depth interval, one can notice that the vertical seismic resolution is not sufficient to describe the heterogeneities inside the reservoir. The only way to increase the vertical resolution is to apply to the depth sections a deconvolution in wave number. The result for the depth section 31 is presented in Figure 13a (upper part). A significant improvement of the vertical resolution is thus obtained.

Full waveform acoustic profiles were recorded along wellbore $\mathrm{C} 1$ and four neighbouring wells, MP6, MP5, M8 and M9 to calibrate the 3D depth seismic block.

The acoustic tool was a monopole tool designed and manufactured by the S.E.M.M. service company. It includes one transducer and two receivers. The distance between the source and the nearest receiver is $3 \mathrm{~m}$ and the distance between the two receivers is $0.25 \mathrm{~m}$. Source and receivers are multidirectional. The transducer generates in the fluid a compressional wavefield which is conveyed in the formation as a compression wave ( $\mathrm{P}$ wave) and a shear wave ( $\mathrm{S}$ wave) at the refraction limit angles. More precisely, in a vertical well, such a tool permits the recording of five propagation modes: the refracted $\mathrm{P}$ wave, the refracted $\mathrm{S}$ wave (only in fast formations - definition below), the fluid wave, and 2 dispersive guided modes (the pseudo-Rayleigh and the Stoneley waves). In a formation, $\mathrm{S}$ waves can be generated only if the $\mathrm{S}$-wave velocity is higher than the P-wave velocity in the mud; the 


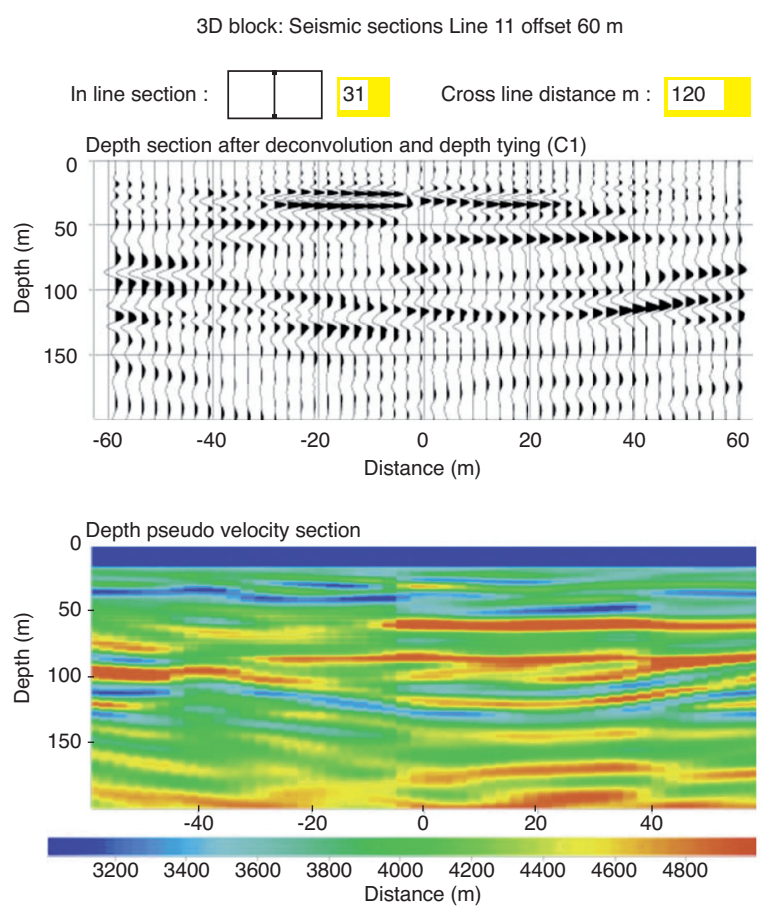

a
C1

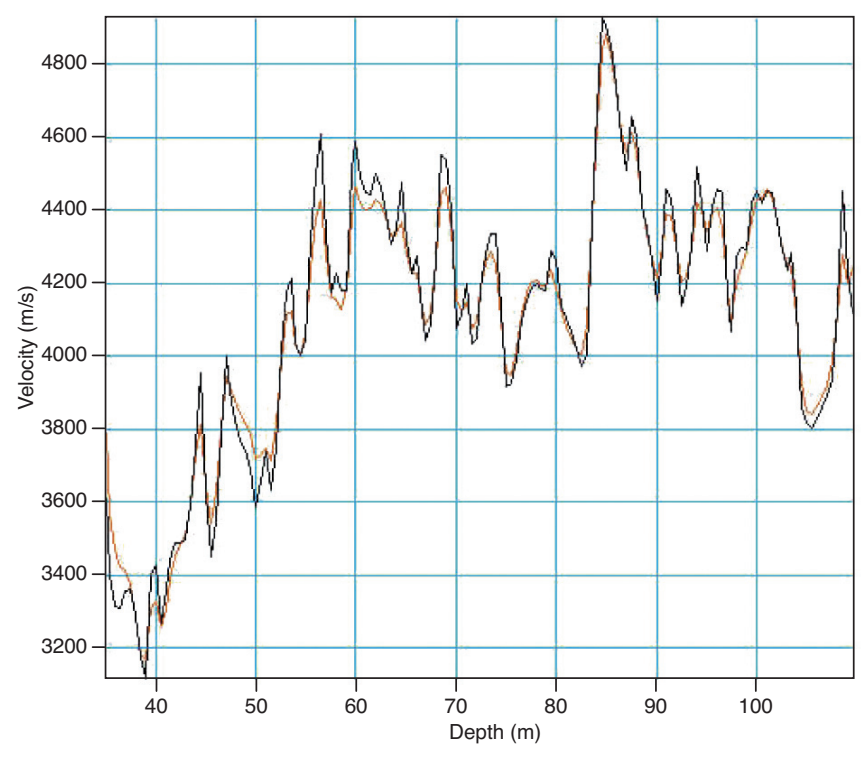

b

Figure 13

Example of deconvolved and pseudo velocity depth sections (in line section 31).

a: Depth section after deconvolution and depth tying (top). Depth pseudo velocity section (bottom).

b: Velocity functions at well $\mathrm{C} 1$ location: velocity function derived from acoustic measurement (black curve), velocity function derived from seismic trace (red curve).

formation is then called a fast formation (contrary to the socalled slow formations).

Figure 14 shows the $3 \mathrm{~m}$ constant offset sections or acoustic profiles recorded in the 5 wells. A constant offset section is a representation versus depth of the recorded waves that are at first the refracted compression wave along the wellbore wall, then the refracted shear wave, and finally the wellbore-conveyed Stoneley waves. The amplitudes of the different waves are coded in different colours. Such a representation allows us to classify the geological entities in acoustic facies. For instance, considering the reference well $\mathrm{C} 1$, three main acoustic units could be defined by the following depth intervals: the 32-60 m unit including a discontinuity at 50-52 m, and two heterogeneous units at $60-85 \mathrm{~m}$ and $85-$ $110 \mathrm{~m}$ that show a fairly similar acoustic facies and are hardly distinguished from one another. However, the sharp velocity change seen at $85 \mathrm{~m}$ on the P-wave velocity log also shown in Figure 14 confirms a major acoustic discontinuity at that depth. The acoustic profile also gives qualitative information about the internal heterogeneity of identified units. Whereas wells M8 and M9 show fairly unaltered waves, wells MP5 and MP6 show perturbed and discontinuous acoustic profiles. In fact, wells MP5 and MP6 reveal themselves as prolific wells contrary to wells M8 and M9 that have a very poor water deliverability. Furthermore, the Stoneley wave response is strongly related to the state of continuity of the well wall along which it travels. In practice, the disappearance of the Stoneley wave at a given level along the wellbore suggests the presence of an open fracture or joint as it can be seen here at a depth of about 50-52 $\mathrm{m}$ for well $\mathrm{C} 1$, and also apparently at depths of 50-53 m and $75 \mathrm{~m}$ for well MP6.

Quantitatively, the picking of the arrival times of the refracted $\mathrm{P}$ wave on the two constant offset sections $(3 \mathrm{~m}$ and $3.25 \mathrm{~m}$ ) gives access to a $\mathrm{P}$ wave velocity $\log$, as shown in Figure 14 for well $\mathrm{C} 1$ (C1 vel.). The raw logs obtained at the 5 wells have been filtered to allow for a $0.5 \mathrm{~m}$ depth sampling. The $\mathrm{P}$ wave velocity logs, with a $0.5 \mathrm{~m}$ depth sampling interval, are displayed in the 35 to $110 \mathrm{~m}$ depth interval and presented in Figure 13b for well C1 (black curves) and in Figure 15 for wells MP6, MP5, M8 and M9 (black curves). 


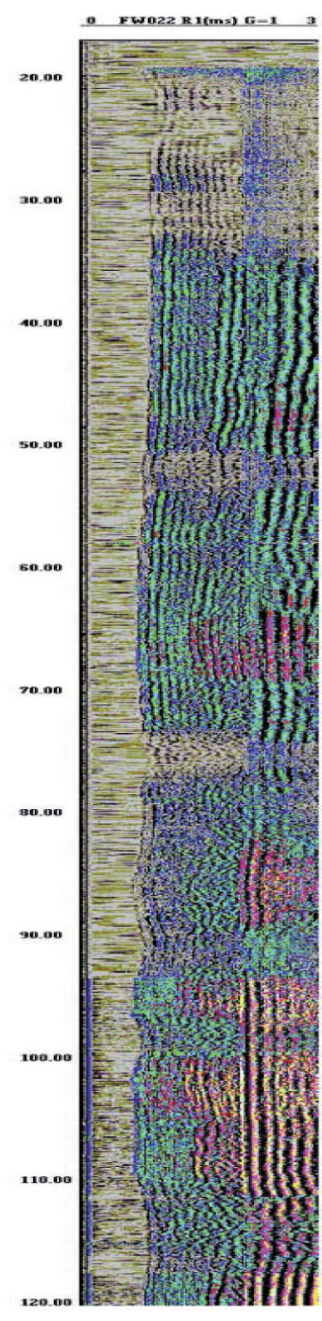

MP6

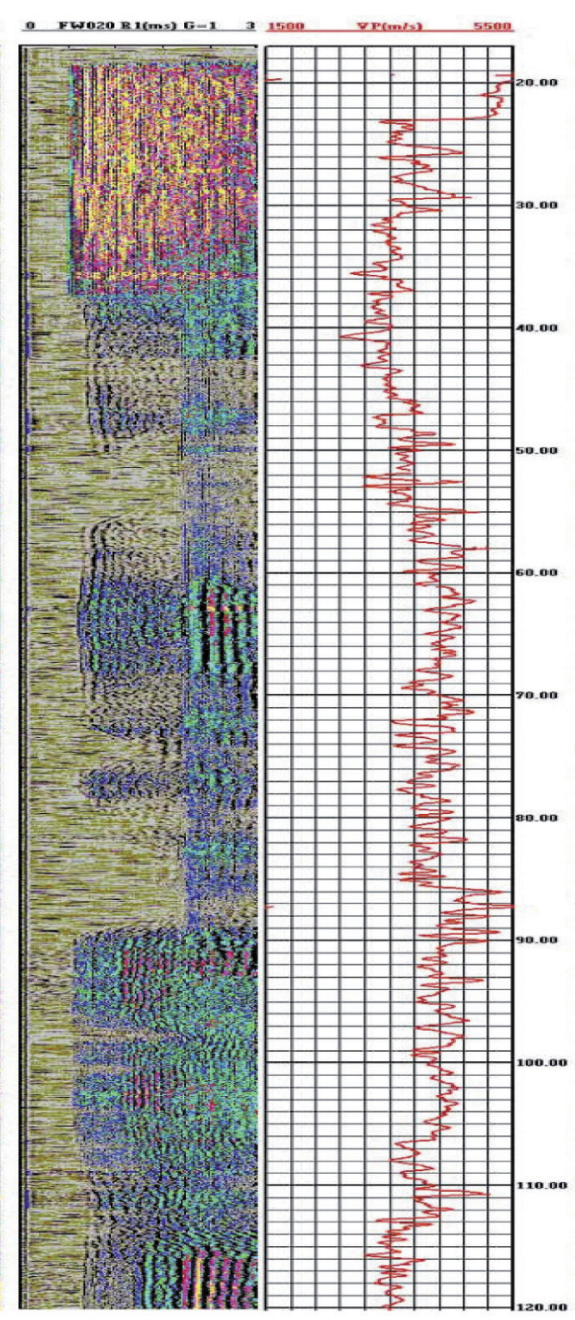

MP5

C1 vel.

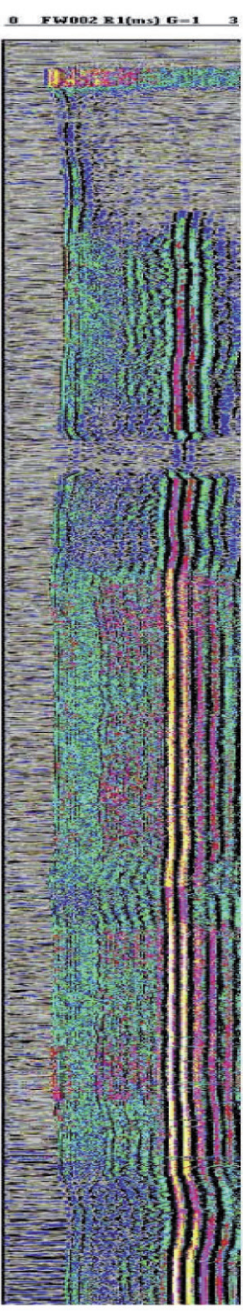

C1

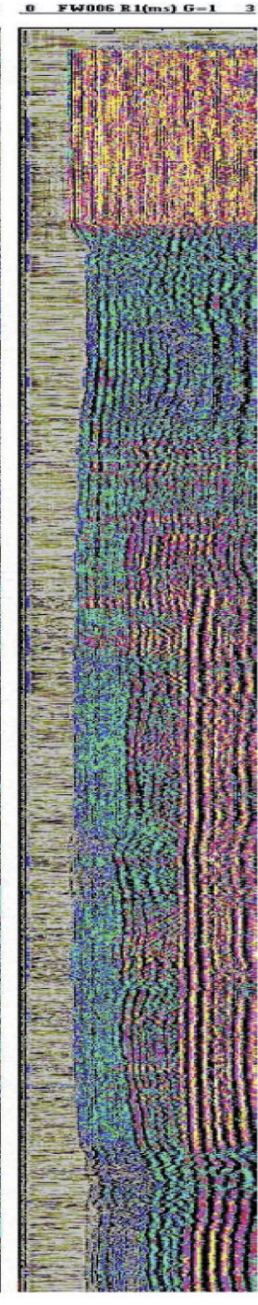

M8

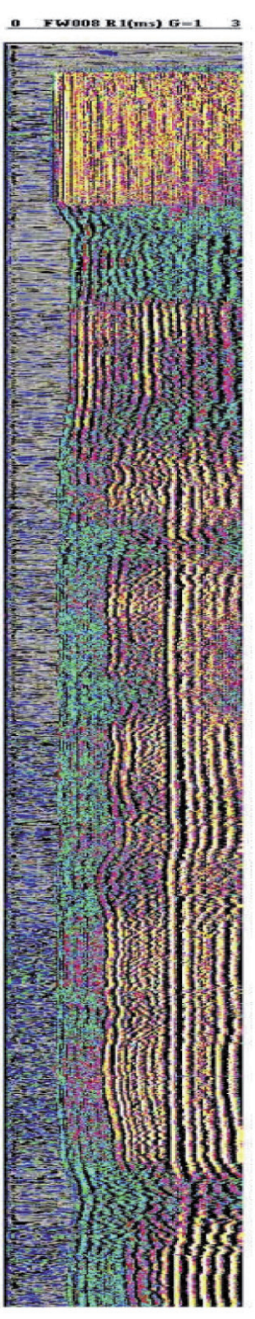

M9

Figure 14

Full waveform acoustic profiles of well $\mathrm{C} 1$ and neighbouring wells. The negative amplitudes are coded in white. The positive amplitudes are coded by a colour scale ranging from grey and green for the low values up to red and black for the high values.

After deconvolution, we assume that the seismic trace represents the reflectivity function of the geological model. Integrating with respect to depth, the deconvolved seismic trace can be constrained to obtain an estimate of the interval velocity function versus depth. For that purpose after deconvolution and integration, a Wiener filter (Mari et al., 1999) has been applied to the seismic traces to convert in velocity the amplitude sections. The Wiener filter is designed to obtain an optimum fit between the acoustic velocity log at well $\mathrm{C} 1$ and the associated deconvolved and integrated seismic trace (Fig. 13b). The Wiener operator thus obtained has been applied to all the deconvolved and integrated traces of the 3D block to transform an amplitude block into a 3D pseudo velocity block in depth. The result obtained with in line depth section 31 is shown in Figure 13 a (bottom). The procedure is validated by measuring correlation coefficients between estimated seismic pseudo velocity logs and acoustic logs at wells MP6, MP5, M8 and M9 (Fig. 15). The correlation coefficients are high. They are equal to 0.98 at well $\mathrm{C} 1$, 0.81 at well M9, 0.79 at well M8, 0.83 at well MP5 and 0.84 at well MP6. To better measure the depth fit between the seismic velocity logs and the acoustic velocity logs, the correlation 


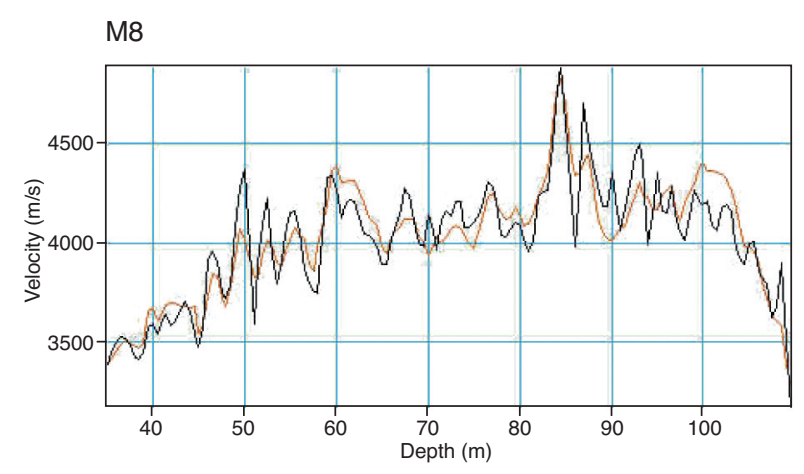

M9

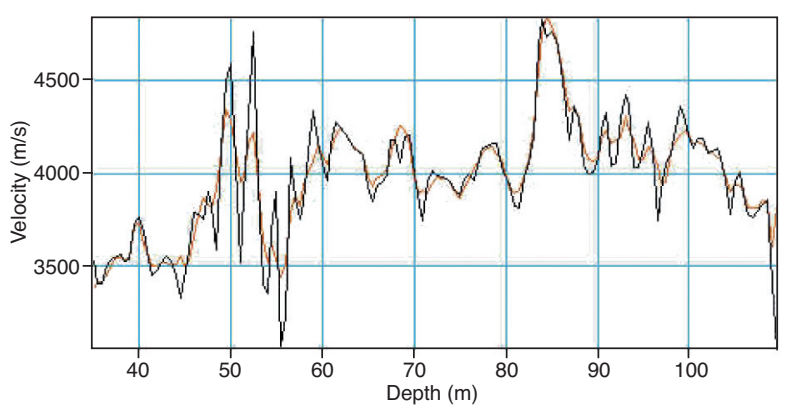

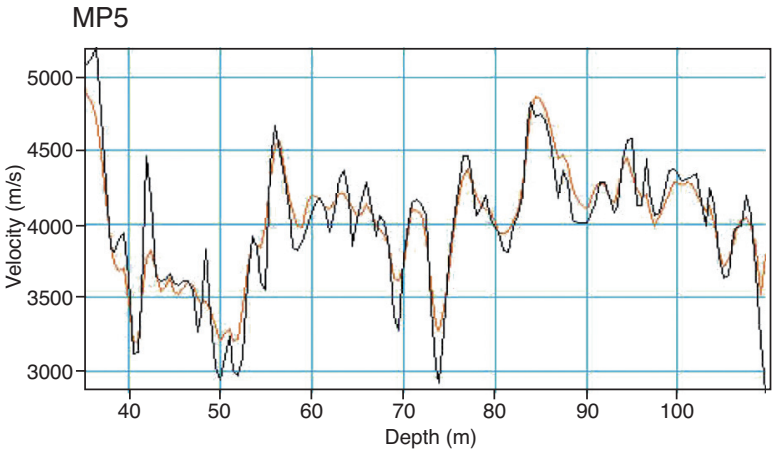

MP6

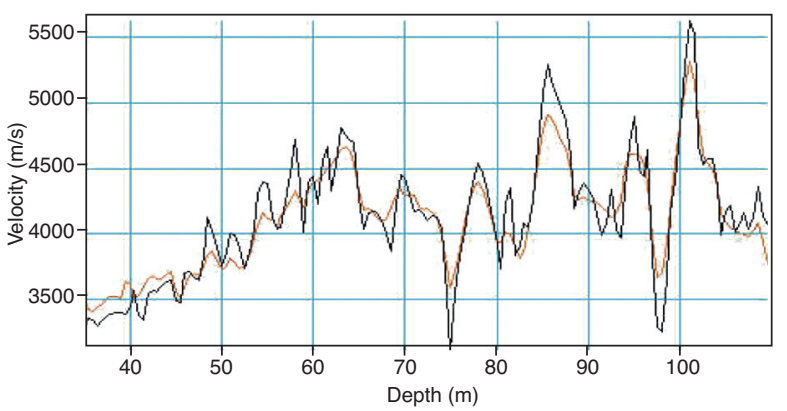

Figure 15

Seismic - Acoustic tying at wells M8, M9, MP5 and MP6. Velocity function derived from acoustic measurement (black curve), velocity function derived from seismic trace (red curve).

coefficients have been computed on the derivatives of the logs. The correlation coefficients are lower. They are equal to 0.945 at well $\mathrm{C} 1,0.67$ at well M9, 0.61 at well M8, 0.78 at well MP5 and 0.75 at well MP6.

The depth pseudo velocity sections thus obtained have been used to obtain velocity maps (Fig. 16) and cross sections at the locations of the deviated wells $\mathrm{C} 3$ and $\mathrm{C} 4$ (Fig. 17). The pseudo velocity maps and the seismic cross sections show the large heterogenity of the aquifer reservoir in the horizontal and vertical planes. The orientation N90 and N50 pointed out by refraction survey are confirmed by reflection survey. At a given depth, the velocity distribution shows preferential connections between wells. As an example, a low velocity zone at $88 \mathrm{~m}$ depth shows a connection between wells M13 and M21; a connection confirmed by well pumping tests and pressure interference measurements. The low velocity areas correspond to high hydraulic conductivity areas. Preliminary studies have shown that flow is mainly located in a few horizontal features interpreted as bedding planes or karstified stratigraphic levels, which are hydraulically connected by sub-vertical fractures.

\section{3D SEISMIC IMAGING AND HYDROGEOLOGY}

The Hydrogeological Experimental Site (HES) covers an area of 12 hectares over which 35 wells were drilled to a depth of $120 \mathrm{~m}$ (Fig. 18). Hydrogeological investigations show that maximum pumping rates vary from well to well and range from 5 to $150 \mathrm{~m}^{3} / \mathrm{h}$.

The interpretation of seismic (refraction) data allowed to map the top of the limestone. This surface was initially flat and horizontal, 150 millions years ago but has been eroded since, during Cretaceous and Tertiary epochs. It is shaped today's as hollows and bumps with a magnitude reaching up 20 meters. Alignments drawn from the geostatistical processing of geophysical data fully agree with the main fracture directions measured by Burbaud-Vergneaud (1987) in the vicinity of Poitiers. Only the so-called South Brittany direction (oriented N135) is not visible since it corresponds to major features separated by lag-distances from several hundred meters to a few kilometres. According to Burbaud-Vergnaud (1987), the fractures are almost vertical and to quantify their density, 3 tilted coresampled boreholes have been drilled. Data from refracted 

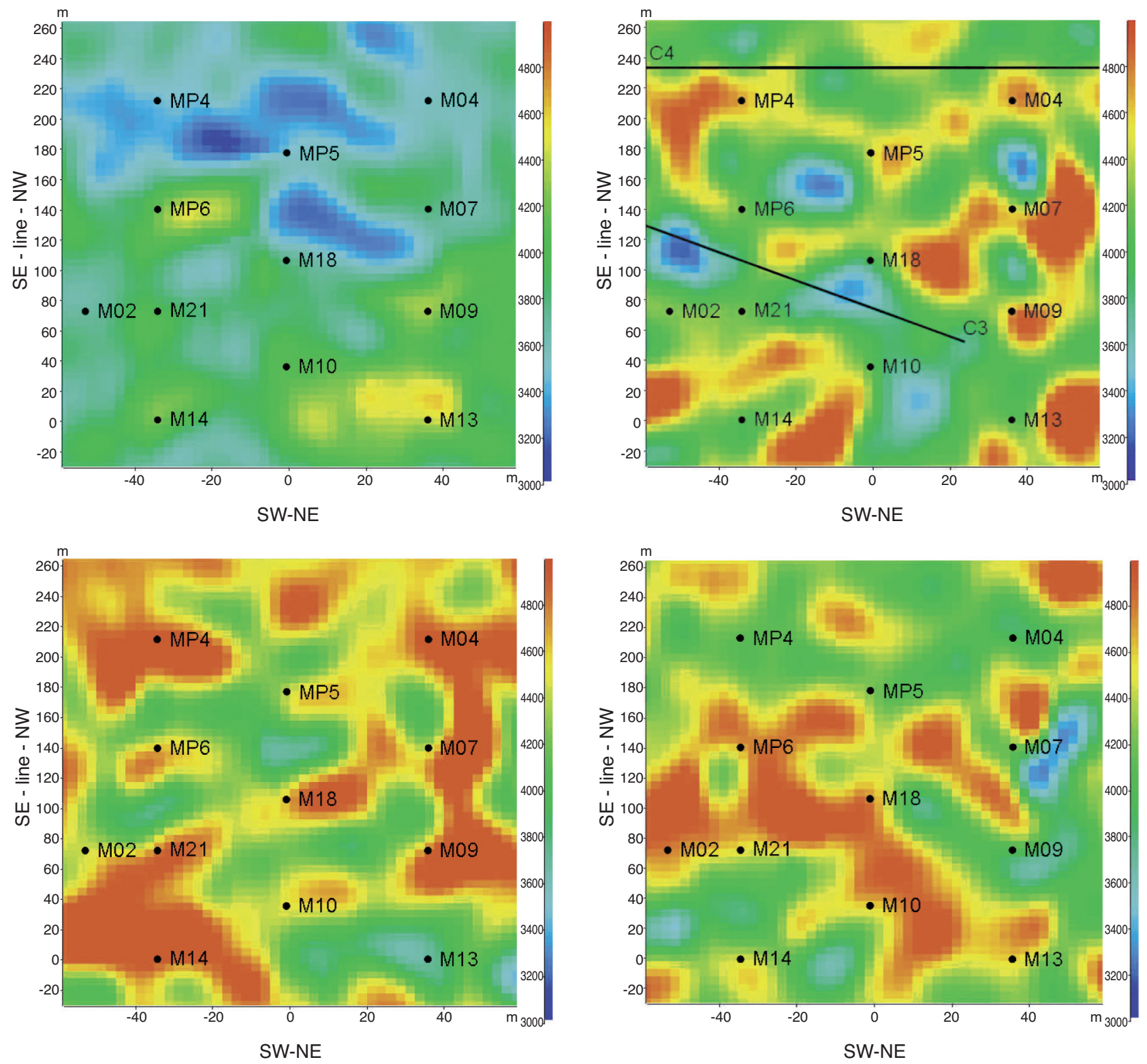

Figure 16

Pseudo velocity maps extracted from the 3D block at different depths $50 \mathrm{~m}$ (top left), $88 \mathrm{~m}$ (top right), $92 \mathrm{~m}$ (bottom left), $102 \mathrm{~m}$ (bottom right). The deviated well locations are indicated on the $88 \mathrm{~m}$ depth map. C3 is oriented N90 and C4 is oriented N50.

seismic revealed very valuable to confirm the directions of the main fracture families, giving then ideas to position boreholes $\mathrm{C} 3$ and $\mathrm{C} 4$. The $\mathrm{C} 3$ borehole was set up along the N90 direction whereas the C4 borehole was aligned along the N45 direction. The next tilted well to be bored (C5) will be oriented N0 in order to cross-cut features oriented N90.

Many hydraulic tests (interference pumping and slugs) have been performed over the HES. Interference testing allows to grasp the hydrodynamic behaviour at the site scale but does not image the local hydraulic connection between wells, even if pressure transients may differ from one observed well to the other (Bernard et al., 2006; Kaczmaryk and Delay, 2007). The slugs show a very rapid propagation of the pressure wave over large distances, say $100 \mathrm{~m}$ on average. These observations allowed to map a diffusivity distribution and the importance of connections between wells (Fig. 19). Preferential connections are visible 

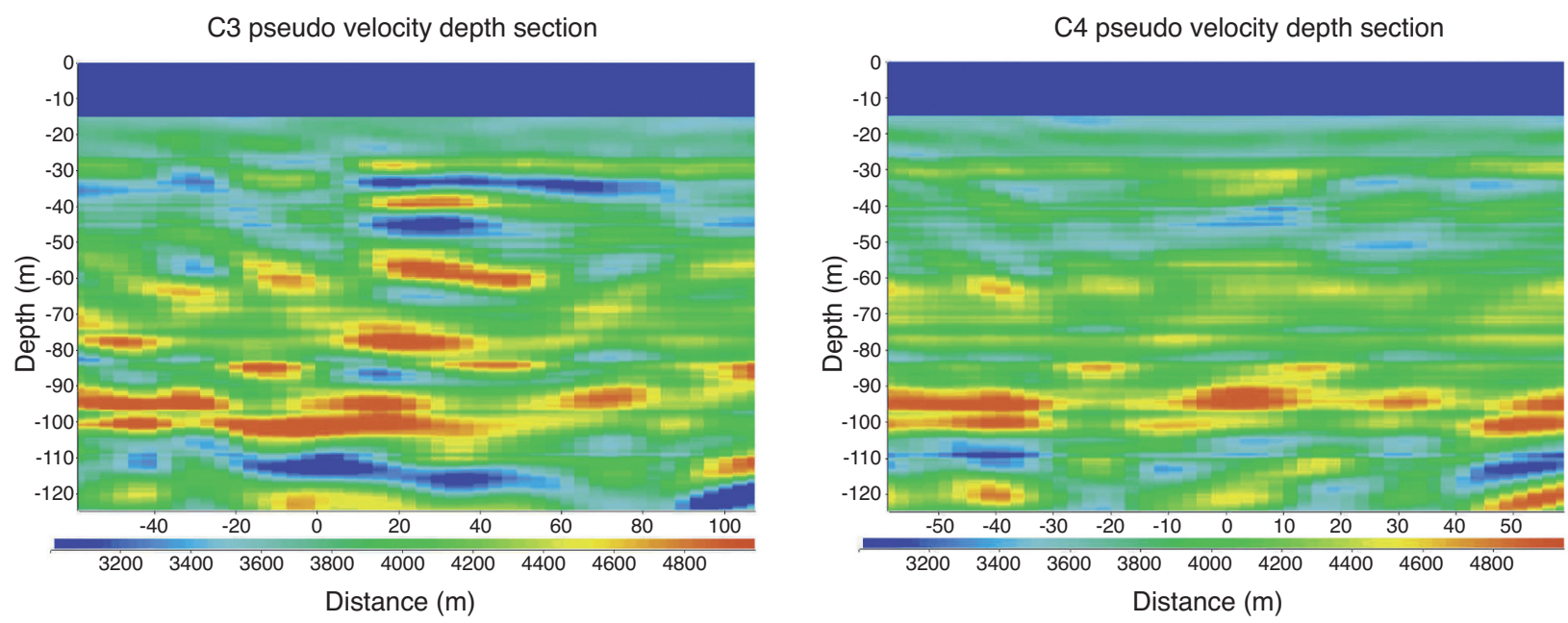

Figure 17

Velocity depth sections at wells C3 and C4 (velocity coded in different colours).

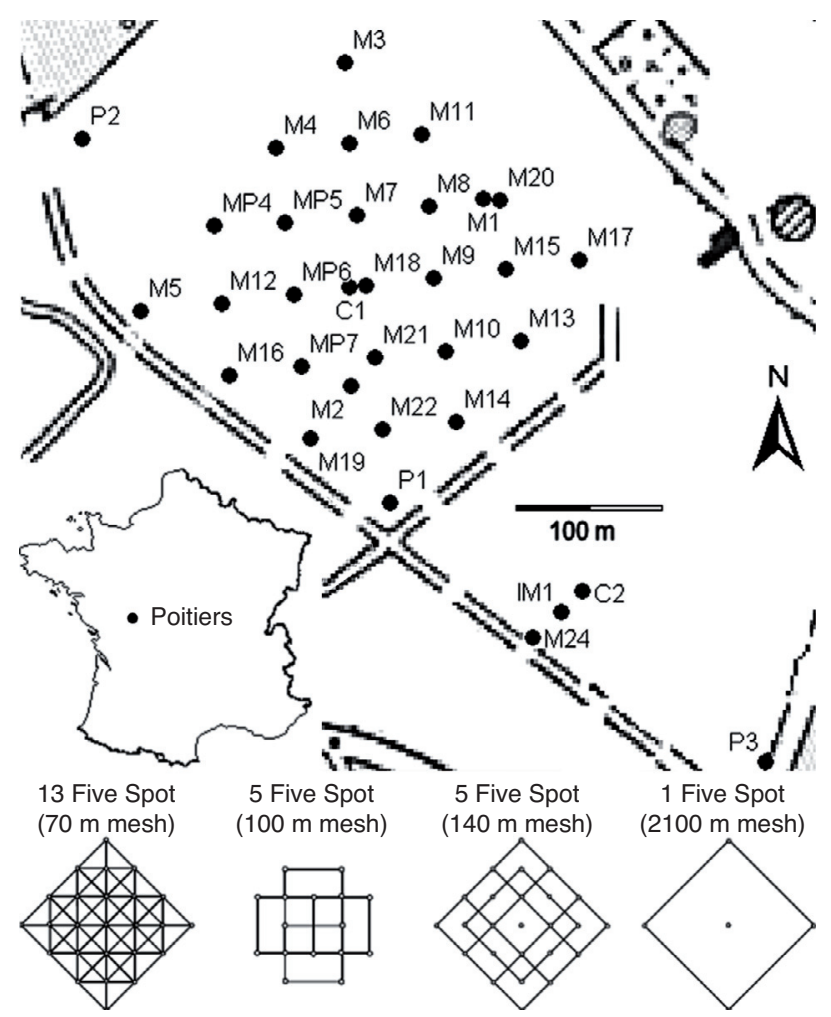

Figure 18

Wells set up as nested five-spot systems in the experimental site in Poitiers. along the N90 direction (wells M13-M21-M22-M19 and wells M04-M06-M11). Incidentally, logging data show 3 water productive layers $(50,88,115 \mathrm{~m}$ depth, respectively). Their presence is not systematic however at each well of the site. The $115 \mathrm{~m}$-depth layer is located on the SW and NW borders of the site whereas the 88 m-layer is present everywhere. The variations of the seismic wave pseudo-velocity at different depths can be compared directly with hydrogeological data. The water-producing level at the depth of $50 \mathrm{~m}$ and observed in wells M18 and M04 obviously corresponds to the weak velocity zones in Figure 16. On the other hand, the wells MP4 and MP5 do not show water production at $50 \mathrm{~m}$ but correspond to small seismic velocities. Their location at the border of the site and the spatial resolution of seismic data are not suited to reveal very local anomalies as those appearing in a channeled karstic system. The map drawn for the $88 \mathrm{~m}$ horizon confirms the hydrogeological data from the majority of wells. Actually, there is an important connection between M13 and M21 which is also visible in the form of a low seismic velocity zone. Thus, it becomes very likely that low velocitiy zones of geophysical maps do correspond to water productive areas. However, a few wells have raised up the existence of clay-infillings from karstic origin which yield also to small seismic velocity that might be erroneously taken as productive zones. This is for instance the case of the area around the wells MP6 and M02. 


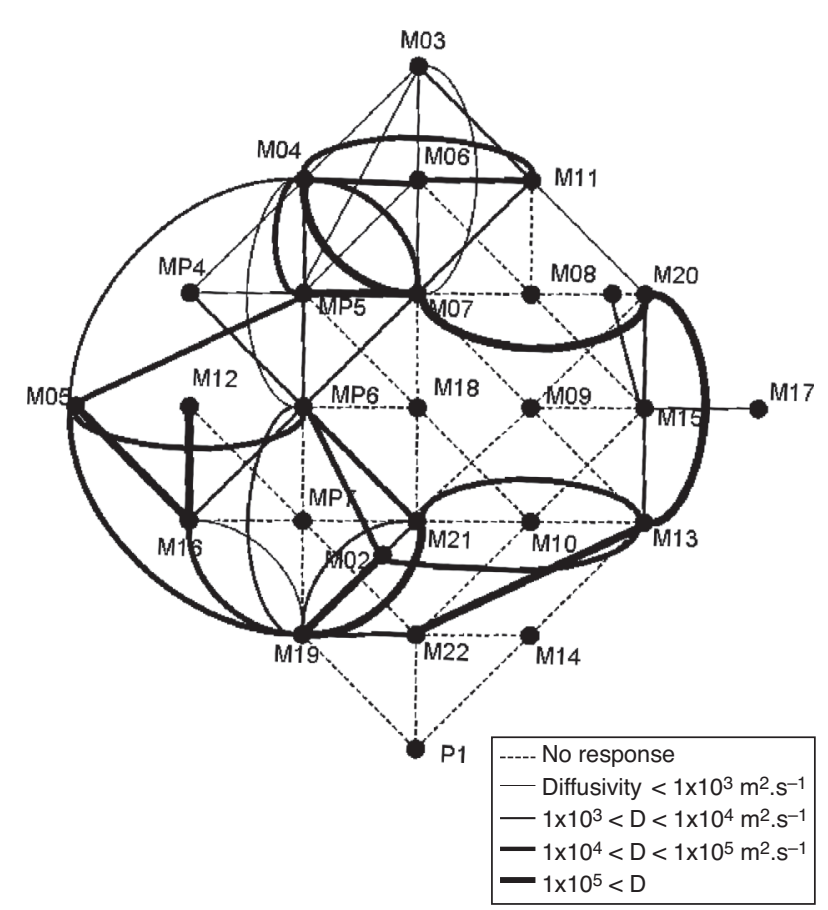

Figure 19

Diffusivity map on the HES from slug-test interpretation.

\section{CONCLUSION}

Different surface seismic surveys have been recorded on an experimental hydrogeological site that has been developed for several years near Poitiers. The paper has shown how 3D seismic imaging can be used to describe the near-surface heterogeneous aquifer. The acquisition spread is designed to perform both $3 \mathrm{D}$ refraction and reflection seismic surveying. The field equipment is reduced to a 48 active channels recorder, a template composed of 48 vertical geophones and small charges of dynamite ( $25 \mathrm{~g}$ per shot point) at each source point.

Refraction survey enables us to obtain a 3D image in depth of a low velocity superficial zone contrasting with the underlying water - bearing carbonates. Variogram analysis and geostatistical filtering allow to filter random acquisition noise. Factorial kriging is used to filter the small scale structures (cubic structure with a range of $55 \mathrm{~m}$ and nugget) in order to make the large scale structures appear and to determine their orientation: a main orientation N90 and a secondary orientation N50. These two directions have been selected to implement two deviated wells C3 and C4.

Reflection survey enables us to obtain a 3D seismic pseudo velocity block in depth. The vertical resolution is enhanced thanks to deconvolution after depth conversion. A Wiener filter has been applied to the seismic traces to convert in velocity the amplitude sections. The operator defined at well $\mathrm{C} 1$ is validated at wells MP6, MP5, M8 and M9.

The 3D seismic pseudo velocity block shows the large heterogeneity of the aquifer reservoir in the horizontal and vertical planes and confirms the main structural orientations (N90 and N50) pointed out by refraction survey. At a given depth, the velocity distribution shows preferential connections between wells. As an example, well pumping tests and pressure interference's confirm the hydrodynamic connection between wells M13 and M21 defined by a low velocity zone at $88 \mathrm{~m}$ depth.

The assessment of the size and connectivity of such presumably-conductive bodies is essential to build a geostatistical model of the site. In this respect, 3D seismic-derived information may help in defining the variogram parameters and the main reservoir regions reflecting the distribution of those conductive bodies and/or their background facies.

\section{ACKNOWLEDGEMENTS}

We thank the University of Poitiers and IFP for permission to use the field data obtained in a common research project. We thank Patrick Meynier (IFP), Pierre Gaudiani (APEC) and the students of Hydrasa for their help in data acquisition. We are grateful to Nicolas Jeannée (Geovariances) for providing useful information and help in geostatistics. We thank Olivier Audouin (Hydrasa) and Bernard Bourbiaux (IFP) for very useful discussions on various occasions.

Seismic data processing has been performed using both Isatis software (www.geovariances.com) and Mustig software (www.gipsa-lab.inpg.fr/mustig).

\section{REFERENCES}

Bernard S., Delay F., Porel G. (2006) A new method of data inversion for the identification of fractal characteristics and homogenization scale from hydraulic pumping tests in fractured aquifers, $J$. Hydrol. 328, 647-658.

Bourbiaux B., Callot J.P., Doligez B., Fleury M., Gaumet F., Guiton M., Lenormand R., Mari J.L., Pourpak H. (2007) Multi-Scale Characterization of a Heterogeneous Aquifer Through the Integration of Geological, Geophysical and Flow Data: A Case Study, Oil Gas Sci.Technol. 62, 3, 347-373.

Burbaud-Vergneaud M. (1987) Fracturation et interactions soclecouverture : le seuil du Poitou. PhD Thesis, University of Poitiers, France.

Caers J. (2005) Petroleum geostatistics, Society of Petroleum Engineers.

Chaouch A., Mari J.L. (2006) 3D land seismic surveys: Definition of geophysical parameters, Oil Gas Sci. Technol. 61, 5, 611-630.

Chilès J.P., Delfiner P. (1999) Geostatistics modeling spatial incertainty, Wiley series in probability and statistics, Wiley, pp. 342-349. 
Hagedoorn G.J. (1959) The Plus-Minus method of interpreting seismic refraction sections, Geophys. Prospect. 7, 158-182.

Kaczmaryk A., Delay F. (2007) Interference pumping tests in a fractured limestone (Poitiers - France): Inversion of data by means of dual-medium approaches, J. Hydrol. 337, 133-146.

Mari J.L., Glangeaud F., Coppens F. (1999) Signal processing for geologists and geophysicists, Editions Technip, $458 \mathrm{p}$.

Mari J.L., Coppens F. (2003) Well seismic surveying, Editions Technip, $238 \mathrm{p}$.
Mari J.L. (2006) Seismic wave separation by SVD and F-K combined filters. Presented at the ISCCSP Conference, Marrakech, February 2006.

Matheron G. (1982) Pour une analyse krigeante des données régionalisées. Internal report N-732, Centre de Géostatistique et de Morphologie Mathématique, École des Mines de Paris, Janvier 1982, $24 \mathrm{p}$.

Palmer D. (1986) Refraction seismics, Geophysical Press, p. 13.

Final manuscript received in September 2007 or distributed for profit or commercial advantage and that copies bear this notice and the full citation on the first page. Copyrights for components of this work owned by others than IFP must be honored. Abstracting with credit is permitted. To copy otherwise, to republish, to post on servers, or to redistribute to lists, requires prior specific permission and/or a fee: Request permission from Documentation, Institut français du pétrole, fax. +33147527078 , orrevueogst@ifp.fr. 


\section{APPENDIX}

\section{REFRACTION SEISMIC: PLUS-MINUS METHOD}

Refraction seismic was the first technique used in oil exploration. In the petroleum sector, it is still very much in use for the determination of characteristics of shallow formation and weathered zone parameters (static corrections). It is currently used in civil engineering and hydrogeology for objective depths less than $300 \mathrm{~m}$. In hydrogeology, the method is particularly suited for highlighting fractured areas or channels carved in bedrock. Refraction imaging of the subsurface is based on the analysis of refraction timedistance curves.

The Plus-Minus method (Hagedoorn, 1959) is widely used in refraction prospecting. Picked times of direct and reverse shotpoints (Fig. Al) give access the $t^{+}$and $t^{-}$curves:

The $t^{-}$curve is obtained by the following equation:

$$
t^{-}(R)=t_{A B D R}-t_{R J F G}+t_{A B F G} \approx \frac{2 R}{V_{2}}+C
$$

The $t^{-}$curve, approximated by a linear equation, provides the velocity $V_{2}$ of the refractor, with dip assumed to be zero locally in the vicinity of point $R$.

The $t^{+}$curve gives a time image of the refractor depth (delay curves). It is given by:

$$
t^{+}(R)=t_{A B D R}+t_{R J F G}-t_{A B F G}=2 D_{R} \approx \frac{2 Z(R) \cos \left(\theta_{c}\right)}{V_{1}}
$$

with $Z(R)$ the depth of refractor at position $\mathrm{R}$ and $\theta_{\mathrm{c}}$ the critical angle defined by:

$$
\sin \left(\theta_{c}\right)=\frac{V_{1}}{V_{2}}
$$

Figure A1 shows that point $\mathrm{H}$ on the refractor, located at

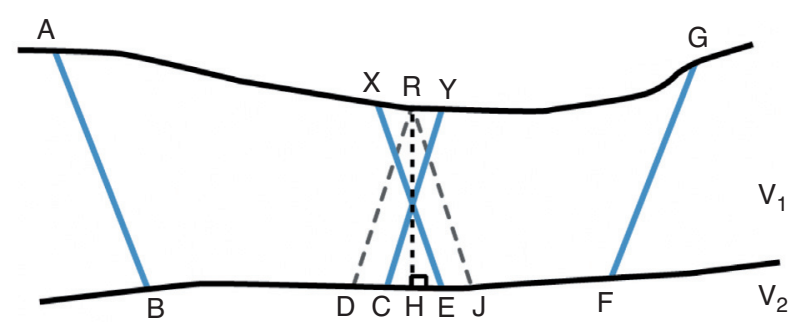

Figure A1

The Plus-Minus method implementation.

Source locations: A and G, receiver locations: X, R, Y.

Assumptions: $\mathrm{R}$ is the midpoint of $\mathrm{XY}, \mathrm{DJ}=\mathrm{CE}+\mathrm{XY}$. the vertical of $\mathrm{R}$ is not reached by the refracted arrival. The layout can be changed to compensate for this drawback. In order to compute the delay time corresponding to a refraction at point $\mathrm{H}$ on the refractor, refracted arrivals must be recorded at sensors $\mathrm{X}$ and $\mathrm{Y}$, for both direct and reverse shooting. The optimum distance XY corresponds to the focusing distance of the forward and reverse raypaths (C coincident with $\mathrm{E}$ and $\mathrm{H}$ ) for which the irregularities in the $t^{-}(\mathrm{R})$ curves are minimised, the $t^{-}$curve provides the refractor velocity. The $t^{+}$and $t^{-}$formula are modified as follows:

$$
\begin{gathered}
t^{-}(R)=t_{A B C Y}-t_{X E F G}+t_{A B F G} \\
t^{+}(R)=t_{A B C Y}+t_{X E F G}-t_{A B F G}-\frac{X Y}{V_{2}} \approx 2 D_{R}
\end{gathered}
$$

Implementation of the Hagedoorn method is modified. The new approach is known as the GRM method (Generalized Reciprocal method). It was introduced by Palmer in 1980.

\section{SOME COMMENTS ON THE REFLECTION SEISMIC PROCESSING SEQUENCE}

The classical approach to seismic processing can be summarized in two main steps.

The first step includes pre-processing of the data and the application of static corrections. The purpose of pre-processing is to extract reflected waves from individual shots, by filtering out the parasitic events created by direct and refracted arrivals, surface waves, converted waves, multiples and noise. It is intended to compensate for amplitude losses related to propagation. Deconvolution operators are applied to improve resolution and harmonize records by taking into account source efficiency variations and eventual disparities between receivers. Any deconvolution is sensitive to noise. A method classically used and relatively robust to noise is the deconvolution with the Wiener filter. The Wiener filter allows passing from a given signal to a wanted signal. The Wiener filter is a filter which minimizes (least squares conditions) the difference between the wanted signal and the signal estimated by the filter. The wanted signal can be a Dirac impulsion. In this case, a geophysician talks of Spiking deconvolution. Static corrections, that are specific to land seismic, are intended to compensate for the effects of the weathered zone and topography. Records are then sorted in common mid-point gathers or common offset gathers.

The second processing step is the conversion of common mid-point gathers or common offset gathers into time or depth migrated seismic sections. This second step includes the determination of the velocity model, with the use of stacking velocity analyses, or tomography methods. The role 
of migration is to place events in their proper location and increase lateral resolution, in particular by collapsing diffraction hyperbolas at their apex. Proper migration requires the definition of a coherent velocity field, which must be a field of actual geologic velocities in migrated positions. Determination of the velocity field is the most critical aspect of migration.

In near surface experimentation's, separation of interfering wave-fields is a crucial step to enhance reflected waves. To achieve it, wave separation filters, such as F-K filters or SVD filters (Singular Value Decomposition), may be used.

Seismic signals, recorded on an array of scalar sensors (singular component sensor) are generally described as summation of several events related to the different sources (reflected, refracted, converted waves, surface waves) propagating through the media. The observed scalar signal depending on time $t$ and space $x$ (a seismic record) is described as:

$$
r(t, x)=\sum_{i} a_{i}(t) * s_{i}(t, x)
$$

where $a_{i}(t)$ is the wavelet of source $i, s_{i}(t, x)$ the propagation vector of the source and $*$ the symbol for the convolution product. Signal $r(t, x)$ can be described in dual domains associated to time and distance variables as:

$S_{\mathrm{i}}(f, x)=F T_{t}\left[s_{i}(t, x)\right]$, the distance-frequency space representation;

$S_{\mathrm{i}}(f, k)=F T_{x}\left[S_{i}(f, x)\right]$, the frequency-wavenumber representation (2D Fourier transforms on time and distance variables).

\section{Filtering in the frequency-wavenumber domain: F-K filter.}

A wave propagating in a non-dispersive medium (with constant velocity $V$ ) can be expressed in time distance domain as: $r(t, x)=w(t-x / V)$. Modulus of the 2D Fourier Transform of $r(t, x)$ gives the representation of the wave in the $f-k$ plane as:

$$
R(f, k)=F T_{t, x}[w(t-x / V)]=W(f) . \delta(k+f / V)
$$

In $f$ - $k$ plane, $\delta(k+f / V)$ represents the straight-line $k+f / V=$ 0 passing through the origin with slope $-1 / V$. In a dispersive medium, the dispersion law is not linear. The wave velocity depends on frequency. Group velocity and phase velocity of the wave can be estimated respectively as $v_{g}=\mathrm{d} f / \mathrm{d} k$ and $v_{\phi}=$ $f / k$. In case of a seismic section with one dispersive event, respectively in time-distance domain and frequency wavenumber domain signal, $r(t, x)$ is written as:

$$
\begin{gathered}
r(t, x)=w(t-x / V) \mathrm{e}^{-i x \phi} \\
R(f, k)=W(f) . \delta(k+f / V+\phi / 2 \pi)
\end{gathered}
$$

In $F-K$ plane, a dispersive wave is characterized by a non-straight line passing through the wavenumber axis at position $k_{\mathrm{o}}$ non-equal to zero. In order to select dispersive waves by a masking filter in $f-k$ plane (fan filter, strip filter), it is necessary to apply a group velocity correction and a phase shift correction (translation of $k_{\mathrm{o}}$ value on the wavenumber axis).

\section{Filtering by Singular Value Decomposition}

After propagation through the media, the received signal $r_{i}(t)$ on sensor $i$ results from the superposition of NS waves $\left[a_{1}(t), \ldots, a_{\mathrm{NS}}(t)\right]$ via the transfer functions $s_{i, p}(t)$.

$$
r_{i}(t)=\sum_{p=1}^{N S} \int s_{i, p}(t-\tau) \cdot a_{p}(\tau)+b_{i}(t) \quad \text { with } i=1, N_{c}
$$

where $b_{i}(t)$ is a noise supposed to be Gaussian, white and centered and $N_{c}$ the number of sensors. With signals sampled in time, we write the received signals in a data matrix as:

$$
\underline{\underline{\mathrm{r}}}=\left[r_{j, i} \mid i=1, \ldots, N_{c} ; j=1, \ldots, N_{t}\right\} \in \mathfrak{R}^{N_{c} \times N_{t}}
$$

The Singular Value Decomposition of the time-space data matrix $\underline{\underline{r}}$ provides two orthogonal matrices $\underline{\underline{u}}$ and $\underline{\underline{v}}$, and one diagonal matrix $\underline{\Delta}$ made up of singular values. The initial data matrix is expressed as:

$$
\underline{\underline{\mathrm{r}}}=\underline{\underline{\mathrm{u}}} \underline{\underline{\underline{\mathrm{v}}}} \underline{\underline{\mathrm{T}}}^{\mathrm{T}}=\sum_{k=1}^{N} \lambda_{k} \underline{\mathrm{u}}_{k} \underline{\mathrm{v}}_{k}^{\mathrm{T}} \text { with } N=\left\{\min N_{c}, N_{t}\right\}
$$

where $\underline{\underline{\mathrm{u}}}=\left[\underline{\mathrm{u}}_{1}, \ldots, \underline{\mathrm{u}}_{k}, \ldots, \underline{\mathrm{u}}_{N}\right]$ is a $N_{c} \times N$ orthogonal matrix made up of left singular vectors $\underline{\underline{u}}_{k}$ giving the amplitude in the real case (amplitude and phase in the complex case), therefore called propagation vectors;

$\underline{\underline{\mathrm{v}}}=\left[\underline{\mathrm{v}}_{1}, \ldots, \underline{\mathrm{v}}_{k}, \ldots, \underline{\mathrm{v}}_{N}\right]$ is a $N_{t} \times N$ orthogonal matrix made up of right singular vectors $\underline{\mathrm{v}}_{k}$ giving the time dependence, hence named normalized wavelets;

$\underline{\Delta}=\operatorname{diag}\left(\lambda_{1}, \ldots, \lambda_{k}, \ldots, \lambda_{\mathrm{N}}\right)$ a $N \times N$ diagonal matrix with the diagonal entries ordered $\lambda_{1} \geq \ldots \geq \lambda_{k} \geq \ldots \geq \lambda_{N} \geq 0$.

The product $\underline{\underline{u}}_{k} \underline{\mathrm{V}}_{k}^{\mathrm{T}}$ is an $N_{c} \times N_{t}$ unitary rank matrix named the $k$ th singular image of data matrix $\underline{\underline{r}}$. Therefore, $\underline{\underline{r}}$ is given by the sum of all the $k$ th singular images multiplied by their correspondent $k$ th singular values $\lambda$. The rank of the matrix $\underline{\underline{r}}$ is the number of non-zero singular values in $\underline{\Delta}$. In the noise free case, if the recorded signals are linearly dependent (for example if they are equal to within a scale factor; that means one wave with an infinite velocity) the matrix $\underline{\underline{r}}$ is of rank one and the perfect reconstruction requires only the first singular image. If the $N_{c}$ recorded signals are linearly independent, the matrix $\underline{\underline{r}}$ is full rank and the perfect reconstruction requires all singular images. 
Using the SVD filter, separation between the signal and the noise subspace is given by:

$$
\underline{\underline{\mathrm{r}}}=\underline{\underline{\mathrm{r}}}^{\mathrm{sig}}+\underline{\underline{\mathrm{r}}}^{\mathrm{noise}}=\sum_{k=1}^{N S} \lambda_{k} \underline{\mathrm{u}}_{k} \underline{\mathrm{v}}_{k}^{\mathrm{T}}+\sum_{k=N S+1}^{N} \lambda_{k} \underline{\mathrm{u}}_{k} \underline{\mathrm{v}}_{k}^{\mathrm{T}}
$$

The signal subspace $\underline{\underline{r}}^{\text {sig }}$ is characterized by the first NS higher singular images (associated to the first NS higher singular values). It gives roughly the waveform of the dominant wave, its energy and its amplitude repartition on the sensors. The reminder subspace $\underline{\underline{r}}^{\text {noise }}$ contains the waves with a low degree of sensor-to-sensor correlation and the noise. In practice, before performing the SVD filtering, a flattening operation on the initial data is applied to obtain an infinite apparent velocity for the selected wave. For refracted waves, the flattening pre-processing is obtained by time shifting the data, the time shifts are derived from the picking of the first arrival times. For dispersive surface waves, the fattening is obtained by group velocity and phase shift corrections. 
